\title{
Review Article Nucleoporin Gene Fusions and Hematopoietic Malignancies
}

\author{
Birthe Fahrenkrog \\ Institute for Molecular Biology and Medicine, Université Libre de Bruxelles, rue Profs. Jeener et Brachet 12, 6041 Charleroi, Belgium \\ Correspondence should be addressed to Birthe Fahrenkrog; bfahrenk@ulb.ac.be
}

Received 7 April 2014; Accepted 9 May 2014; Published 27 May 2014

Academic Editor: Brij B. Singh

Copyright (C) 2014 Birthe Fahrenkrog. This is an open access article distributed under the Creative Commons Attribution License, which permits unrestricted use, distribution, and reproduction in any medium, provided the original work is properly cited.

\begin{abstract}
Nuclear pore complexes (NPCs) are the sole gateways between the nucleus and the cytoplasm of eukaryotic cells and they mediate all macromolecular trafficking between these cellular compartments. Nucleocytoplasmic transport is highly selective and precisely regulated and as such an important aspect of normal cellular function. Defects in this process or in its machinery have been linked to various human diseases, including cancer. Nucleoporins, which are about 30 proteins that built up NPCs, are critical players in nucleocytoplasmic transport and have also been shown to be key players in numerous other cellular processes, such as cell cycle control and gene expression regulation. This review will focus on the three nucleoporins Nup98, Nup214, and Nup358. Common to them is their significance in nucleocytoplasmic transport, their multiple other functions, and being targets for chromosomal translocations that lead to haematopoietic malignancies, in particular acute myeloid leukaemia. The underlying molecular mechanisms of nucleoporin-associated leukaemias are only poorly understood but share some characteristics and are distinguished by their poor prognosis and therapy outcome.
\end{abstract}

\section{Introduction}

1.1. Nuclear Pore Complexes. The nuclear envelope (NE) serves as a boundary that separates nuclear and cytoplasmic compartments to protect the genome. This compartmentalization necessitates the transport of RNAs and proteins across the NE and this bidirectional macromolecular trafficking occurs through nuclear pore complexes (NPCs) [1, 2]. NPCs are large multiprotein assemblies, which both in vertebrates and yeast consist of $\sim 30$ different proteins, known as nucleoporins or Nups, [3-5]. Nucleoporins assemble into repetitively arranged subcomplexes to form NPCs with the pseudo-8-fold rotational symmetry [6-10]. In total, NPCs are estimated to be formed from about 500-1000 individual proteins $[10,11]$, which account for a molecular weight of about $110 \mathrm{MDa}$ in vertebrates, according to scanning transmission electron microscopy and proteomic analyses $[4,10,12]$.

The principle structural organization of the NPC has been determined by distinct electron microscopy (EM) approaches, including cryo-EM tomography, mainly in Xenopus laevis oocyte nuclei, but also in yeast, amoebozoa, plants, and human and appears as evolutionary conserved $[6,9,10$, 13-19]. Overall, NPCs are characterized by a roughly tripartite architecture: a central framework (also known as spoke complex, spoke-ring complex, or scaffold-ring complex) that is decorated with eight cytoplasmic filaments and a nuclear basket, which, in turn, is formed from eight filaments that join into a distal ring (Figure 1(a)). The central framework consists of eight spokes (i.e., the scaffold or the spoke-ring) that are flanked by the cytoplasmic and nuclear ring moieties and it encloses a central pore (or central channel), which accomplishes the nuclear-cytoplasmic exchange $[1,2]$. The central, hour-glass shaped pore of the NPC has a diameter of $60-80 \mathrm{~nm}$ at its cytoplasmic and nuclear periphery and $\sim 40-$ $45 \mathrm{~nm}$ in the midplane of the NE (Figure 1(b)) $[9,10,14,15,19-$ 21]. Macromolecules with a diameter up to $\sim 39 \mathrm{~nm}$ can pass the central pore in a signal-, receptor-, and energy-dependent manner, while smaller molecules up to $\sim 9 \mathrm{~nm}$ in diameter can diffuse between the nucleus and the cytoplasm [2124]. Despite an overall resemblance in the $3 \mathrm{D}$ architecture, NPCs from different species show significant variance in their protein density, most likely due to variations in nucleoporin sequence, position, and number, in their linear dimensions, and in the overall number of NPCs per nucleus in distinct species $[4,16,25-27]$.

On the molecular level, NPCs are built of the about 30 different nucleoporins. Nucleoporins fall into three some groups with respect to their amino acid sequence and 


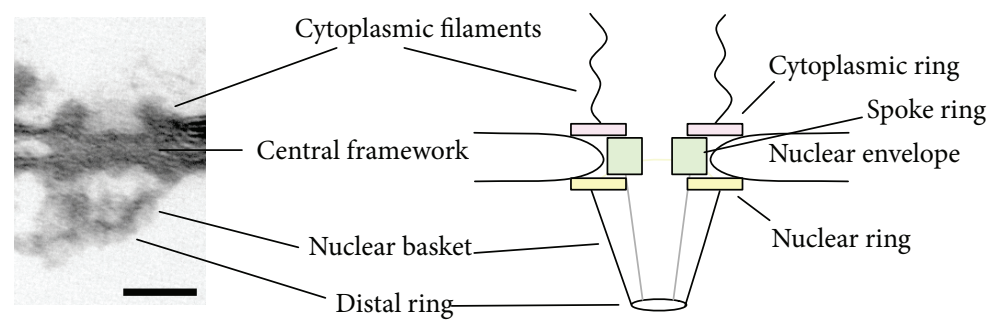

(a)

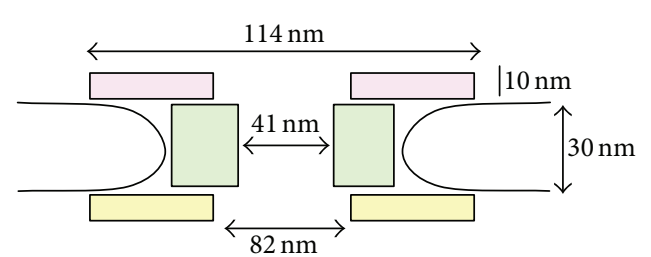

(b)

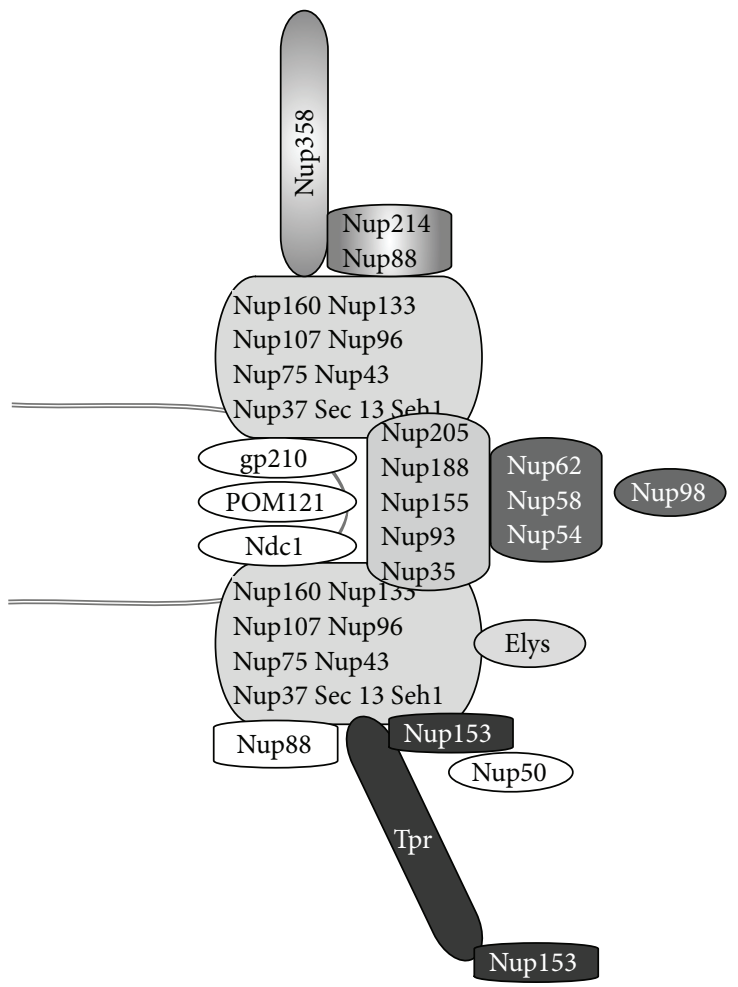

(c)

FIGURE 1: Schematic representation of nuclear pore complex (NPC) architecture, subcomplex composition, and localization within the NPC. (a) Xenopus oocyte nuclei have millions of closely packed NPCs and a cross-section along an embedded nuclear envelope from these nuclei offer side views of NPC architecture that can be visualised by transmission electron microscopy. Shown are a selected NPC in side view (left) and a schematic diagram of the main structural components of NPCs (right). Scale bar, $100 \mathrm{~nm}$. (b) Linear dimensions of the central framework of the human NPC. Numbers are according to [10]. (c) Nucleoporins can be classified in different subgroups depending on their structural motifs and their localization: transmembrane proteins (white), scaffold nucleoporins (light grey), nucleoporins of the cytoplasmic filaments (gradient), central channel nucleoporins (middle grey), and nuclear basket nucleoporins (dark grey). Nup153 has two anchoring domains at the nuclear basket, the $\mathrm{N}$ terminus close to the nuclear ring and a zinc-finger domain at the distal ring of the nuclear basket. Nup88 is also found in the proximity of the nuclear ring and Nup50 is a mobile nucleoporin associated with the nuclear basket.

predicted structural motifs [28, 29]. Accordingly, transmembrane proteins, which in metazoans are comprised of gp210, Ndc1, and POM121, anchor the NPC to the NE. These nucleoporins reside at the boundary between the central framework and the pore membrane (Figure 1(c)). The scaffold of the NPC is made of nucleoporins containing $\alpha$-helical solenoid and $\beta$-propeller fold motifs. This group of nucleoporins includes the Nup107-160 complex, which represents the major constituent of the cytoplasmic and the nuclear ring moieties $[10,30,31]$ as well as the Nup93 complex, which is located towards the central pore of the NPC (Figure 1(c)). The third group of nucleoporins is characterized by the presence of repetitive phenylalanine-glycine (FG) motifs and/or by coiled-coil motifs $[28,29]$. Individual FG motifs are typically interspersed by hydrophilic linkers of variable length and composition and these FG-Nups are typically engaged in nucleocytoplasmic transport. The Nups of the third group can be further subdivided into nucleoporins of the cytoplasmic filaments, such as Nup358 and Nup214, nucleoporins of the central channel, such as Nup98 and the Nup62 complex, and the nuclear basket nucleoporins Nup153, Nup50, and Tpr (Figure 1(c)).

During interphase, nucleoporins exhibit multiple functions, not only as structural elements and facilitators of 
nucleocytoplasmic transport, but also as key players in the regulation of gene expression [32-38]. At the onset of mitosis, NPCs disassemble along with the NE. During this disassembly stage, nucleoporins frequently stay in their subcomplexes, some of which associate with mitotic structures, such as kinetochores or the mitotic spindle. As a consequence, the function of these nucleoporins has been linked to mitotic processes like spindle formation, kinetochore function, and the spindle assembly checkpoint (SAC) [39-41]. Nucleocytoplasmic transport, gene expression, and mitosis are highly specific and tightly regulated processes that are important aspects of normal cellular function. Not surprisingly, nucleoporin dysfunction has been linked to human pathologies, including various forms of cancer. Of particular interest in this context are the three nucleoporins Nup98, Nup214, and Nup358, which are recurrent targets for chromosomal translocations leading to human hematopoietic malignancies, in particular acute myeloid leukaemia.

1.2. Acute Myeloid Leukaemia. Leukaemias are a biologically and clinically heterogeneous group of malignant disorders that are grouped into chronic and acute leukaemia, among which the acute leukaemias are having the more aggressive presentation. Among the acute leukaemias, $~ 80 \%$ are acute myeloid leukaemia (AML) and $\sim 20 \%$ acute lymphoblastic leukaemia (ALL). AML represents a genetically and phenotypically highly heterogeneous disease characterised by blocked differentiation and uncontrolled proliferation of haematopoietic precursor cells, which coincides with an increase in their self-renewal capacities [42, 43]. Based on WHO classification, AML falls into four main groups: AML with recurrent genetic abnormalities, AML with myelodysplasia-related changes, therapy-related AML and MDS, and AML that does not fit into any of these groups. The origin of AML is associated with two classes of mutations: class 1 mutations enhance proliferation signalling pathways, such as Flt3 kinase and NRas/KRas signalling, whereas class 2 mutations target the transcription machinery coinciding with impaired haematopoietic differentiation conferring the selfrenewal ability of haematopoietic precursor cells. A frequent target for transcriptional misregulation in AML is the HOXA locus [43]. HOX genes are expressed sequentially during embryonic development and in haematopoiesis. Expression of HOXA7, HOXA9, and HOXA10 promotes stem cell selfrenewal, and downregulation of these gene clusters coincides with terminal differentiation [44]. In $70-80 \%$ of human AML, HOXA7, HOXA9, and HOXA10 are overexpressed, together with one of the Hox cofactors, Meisl (myeloid ectropic insertion site) or PBX (pre-B-cell leukaemia) [43, 45]. HOXA gene aberrations alone, however, are not sufficient to initiate leukaemogenesis $[46,47]$ and are therefore often accompanied by class I mutations (see above), by aberrant formation of complexes with histone-modifying enzymes, such as the histone deactelyase complex (HDAC), as well as by modifications in DNA methylation and micro-RNAs $[48,49]$.

Recurrent chromosomal translocations found in AML are $\mathrm{t}(8 ; 21)(\mathrm{q} 22 ; \mathrm{q} 22)$ resulting in $A M L 1-E T O$ and $\mathrm{t}(15 ; 17)(\mathrm{q} 22 ; \mathrm{q} 12)$ resulting in $P M L-R A R \alpha$, rearrangements involving the MLL1 (mixed lineage leukaemia) gene on 11q23, and also the nucleoporins Nup98, Nup214, and Nup358. AML with $t(8 ; 21)$ and $t(15 ; 17)$ have a relatively good prognosis, MLL translocations typically an intermediate prognosis [50], whereas AML associated with nucleoporins often have a poor prognosis $[51,52]$. One reason for the poor prognosis might be the upregulation of HOXA9, which is highly correlated with worst treatment outcome and disease relapse and which is frequently coinciding with Nup98 and Nup214 translocations $[43,53]$. However, HOXA9 activation is a prevalent but not a uniform hallmark of nucleoporin-associated haematopoietic malignancies.

\section{Nucleoporins in Leukaemia}

2.1. The Nucleoporin Nup98. Nup98 is a rather mobile FG nucleoporin, which dynamically associates with NPCs in a transcription-dependent manner $[54,55]$. The NUP98 gene is located on human chromosome 11 and it encodes two major transcripts: NUP98 and NUP98-NUP96 [56, 57]. Both give rise to protein precursors, which are cleaved into a 98-kDa N-terminal and an 8-kDa C-terminal peptide and Nup98 and Nup96, respectively (Figure 2(a)). The mature cleaved proteins are generated by autoproteolytic cleavage of Nup98, which is critical for its correct targeting to NPCs $[56,58,59]$. Based upon its amino acid sequence Nup98 is comprised of two major domains (Figure 2(b)): an N-terminal GLFG (glycine-lysine-phenylalanine-glycine) domain and a C-terminal autoproteolytic domain [59]. Different forms of FG-domains are found in approximately onethird of the nucleoporins and Nup98 is the sole vertebrate GLFG-nucleoporin. FG domains mediate the interaction of nucleoporins to soluble nuclear transport receptors and Nup98 binds the nuclear protein export factor CRM1 [60, 61] as well as the mRNA export factor TAP/NXF1 $[62,63]$. The repeat domain of Nup98 contains a distinct region, the Gle2-binding sequence (GLEBS), which provides binding sites for its partner Rael/Gle2 [64, 65]. The GLFG region further associates with the CREB-binding protein $\mathrm{CBP} / \mathrm{p} 300$, which acts as transcriptional coactivator [66]. The C-terminal domain of Nup98 provides the binding site for Nup88 [67], a nucleoporin which is found overexpressed in various human tumours [68, 69]. Nup98's C terminus further contains a so-called nucleoporins RNA-binding motif (NRM), which is, however, most likely not binding RNA $[58,70]$, and it harbours the autoproteolytic cleavage site (Figures 2(a) and 2(b)).

The localization of Nup98 is typically restricted to the nucleus and two nuclear pools have been described: one at NPCs and a second one in the nucleoplasm [34, 54, 60]. In a few cases, however, an extranuclear localization of Nup98 has been observed: in C. elegans, it was also found in the cytoplasm in association with $\mathrm{P}$ granules, but not P bodies, and in mice Nup98 was detected in germ granules [71]. Within NPCs, the anchoring C-terminal domain is tethering Nup98 to the centre of the NPC $[72,73]$, whereas the FG domain can be seen on both the cytoplasmic 


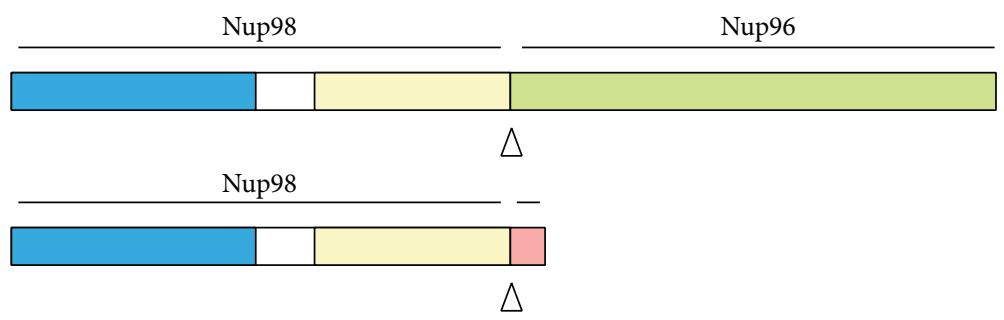

(a)
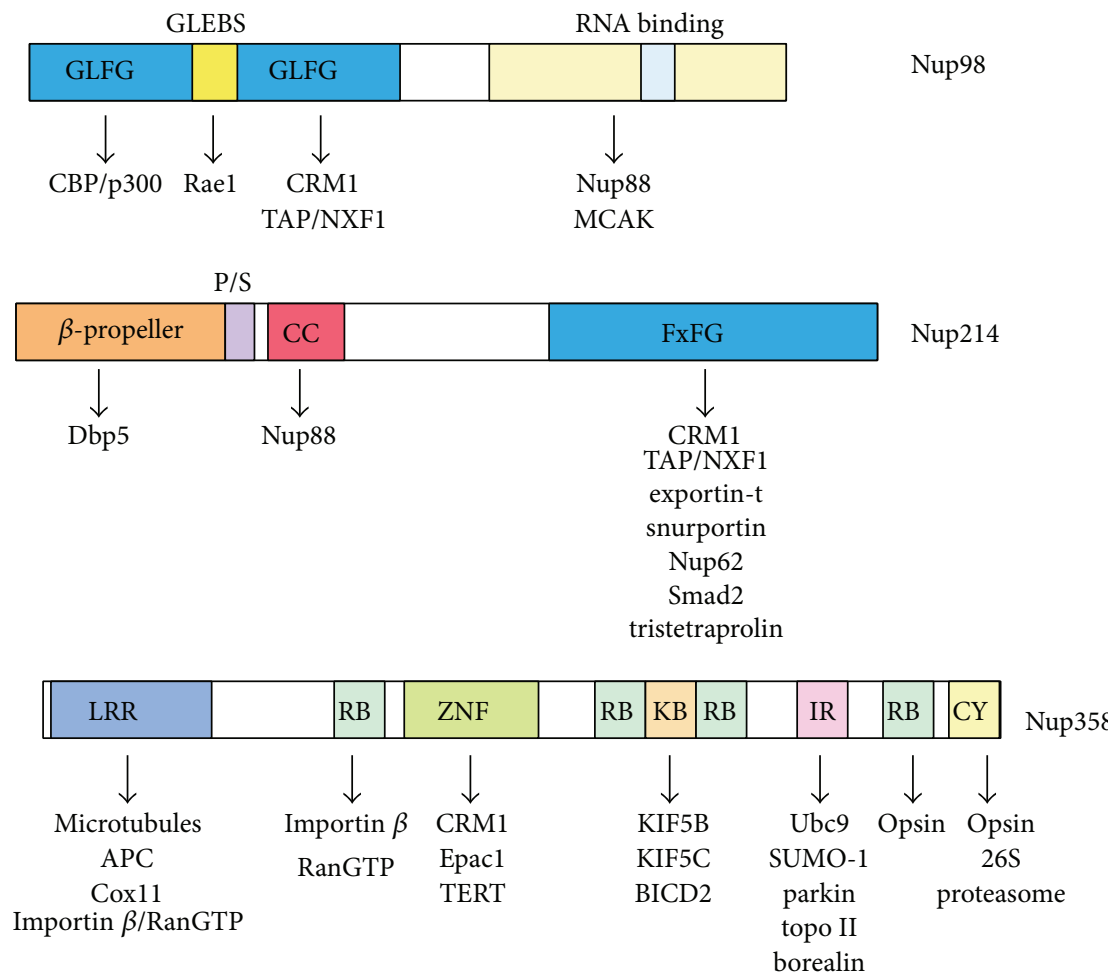

(b)

FIGURE 2: Molecular features of nucleoporins. (a) Nup98 is generated by autocleavage of the Nup98-Nup96 and Nup98 precursor, respectively. Cleavage occurs due to an intrinsic peptidase activity (indicated by the white arrow heads). (b) Schematic representation of Nup98, Nup214, and Nup358 domain organization and their binding partners. P/S: proline-serine rich; CC: coiled-coil; LRR: leucine-rich region; RB: Ranbinding domain; ZNF: zinc-finger domain; KB: kinesin-binding domain; IR: internal repeats (E3 ubiquitin ligase domain); CY: cyclophilin A homology domain.

and the nuclear periphery of NPCs. FG domains have little secondary structure and are considered as disordered [7478], which assures a high structural flexibility of these domains and alternating locations within the NPC $[6,73,79-$ 82].

Nup98 is an important player in nucleocytoplasmic transport and exhibits multiple roles in RNA export from and protein import into the nucleus $[62,83-89]$. Moreover, it serves as a mobile cofactor for the protein export factor CRM1, in concert with the CRM1-cofactor RanBP3 [60]. Consistent with its tethering to the centre of NPCs, Nup98 acts as the major constituent of the NPC's permeability barrier [90], which assures the selectivity of nucleocytoplasmic transport.

Modulating gene expression is another important function of Nup98. It was first noticed in Drosophila that the intranuclear fraction of Nup98 is localized to promoters of developmentally regulated genes [36, 91]. More recently, Nup98 was shown to bind to developmentally regulated genes that are active during differentiation of human embryonic stem cells [35]. Interestingly, genes that are active during early developmental stages bind to Nup98 at NPCs, whereas genes active at later stages associate with the intranuclear pool of Nup98 [35]. Nup98 is furthermore promoting epigenetic transcriptional memory for interferon- $\gamma$-inducible genes. Typically, interferon- $\gamma$-inducible genes are more rapidly and strongly activated in cells that have been treated with interferon- $\gamma$ before as compared to untreated cells and this transcriptional memory is lost in cells lacking Nup98 [92]. The recently expressed promoters exhibit a persistent histone $\mathrm{H} 3$ lysine 4 dimethylation $(\mathrm{H} 3 \mathrm{~K} 4 \mathrm{me} 2)$ and are poised with 
RNA polymerase II (pol II). In cells lacking Nup98, pol II does not remain associated with promoters, and the $\mathrm{H} 3 \mathrm{~K} 4 \mathrm{me} 2$ mark is lost, just as the transcriptional memory. The role for Nup98 in promoting epigenetic transcriptional memory for inducible genes appears conserved from yeast to humans [92].

Beyond transcription, Nup98 affects gene expression also posttranscriptionally: Nup98 prevents p21 mRNA degradation by the exosome, likely due to a role in p21 mRNA export [93]. Nup98 binds directly to the $3^{\prime}$ UTR of p21, a key effector of the p53 pathway, but not to several other p53 targets. As p21 is an important inhibitor of cell death under stress conditions, liver cells depleted for Nup98 are prone to camptothecininduced apoptosis, while they have a reduced capability for undergoing cellular senescence [93]. Interestingly, Nup98dependent downregulation of p21 appears to be a hallmark in a significant fraction of hepatocellular carcinomas (HCC): Nup98 is largely reduced in an HCC mouse model as well as in patients with HCC [93]. The downregulation of Nup98 in patients was associated with a reduction in p21 levels. Beyond NCT and gene expression, roles in DNA replication in Xenopus reconstituted nuclei [85] and in DNA damage response in Aspergillus nidulans [94] have been assigned to Nup98. During mitosis, Nup98 regulates mitotic spindle assembly due to a direct association with microtubules and the depolymerizing kinesin MCAK [95]. In addition, Nup98, in association with the mRNA export factor and nucleoporin Rael (also known as Gle2) [65], is impacting the timing of mitotic exit by preventing securin degradation by the anaphase promoting complex $[96,97]$.

2.2. Chromosomal Translocations Involving NUP98. The NUP98 gene, located on chromosome 11p15, is frequently involved in balanced chromosomal translocations that juxtapose the N-terminal GLFG domain of Nup98 to the C terminus of a partner gene. The breakpoint in NUP98 is in most cases between intron 11 and 13. In contrast to Nup98, the fusion proteins do not associate with NPCs but are found in the nucleoplasm, often in a very distinctive pattern (see, e.g., [98]). The GLFG domain of Nup98 needs to be intact for cellular transformation and it can act as both transcriptional coactivator and corepressor [66]. The first identified as well as most frequent and best-studied chimera is NUP98-HOXA9 [51, 99, 100] and since its discovery in 1996 about 30 distinct partner genes for NUP98 have been identified. NUP98 rearrangements are primarily associated with de novo and therapy-related acute myeloid leukaemia (AML), and also with myelodysplastic syndrome (MDS), chronic myelogenous leukaemia (CML), and T cell acute lymphoblastic leukaemia (T-ALL) [51, 101-103]. Nup98associated leukaemias are rare but recurring and characterised by their aggressiveness and disappointing treatment outcome [51, 101, 103]. Compared to other AML patients, patients with NUP98 translocations are younger and have a poorer overall and a poorer relapse-free survival $[104,105]$.

The partner genes of NUP98 can be roughly divided into two groups: 10 homeobox domain (HD) genes and 20 nonHD genes (Table 1). HD proteins are transcription factors that play crucial roles during development and haematopoiesis and they are characterized by their DNA-binding HD domain [106]. The non-HD partners of Nup98 often contain histone "reading" and "writing" domains, such as PHD fingers and SET domains; the partners are RNA helicases and DNA topoisomerase, and about one-third of the Nup98 partners lack any RNA, DNA, or histone binding activity but are harbouring protein-protein interaction motifs and coiledcoil domains (Table 1) [51]. In contrast to the variety in the C-terminal partner, the presence of the N-terminal GLFG domain of Nup98 is a mutuality of all fusion proteins and their expression is driven by the NUP98 promoter [51]. How the fusions of Nup98 with so many different partners can cause similar disease phenotypes and drive leukaemogenesis has remained largely elusive.

Malignant cells in AML are characterised by continuous proliferation and aberrant differentiation. The impaired differentiation of hematopoietic precursor cells is attributed to the activation of the HOXA9 locus, which in fact is frequently coinciding with Nup98 chimeras [45, 107-113]. $H O X$ activation is controlled by the trithorax proteins, whereas their silencing is regulated by polycomb proteins [42]. Spreading of polycomb proteins and silencing of the HOXA locus appear to be prevented by binding of PHD fingers adjacent to the HOXA7 and HOXA9 locus, which maintains methylation of histone $\mathrm{H} 3$ at lysine 4 and lysine 36 , respectively, and histone acetylation, at least for Nup98 fusions containing PHD fingers, such as Nup98-NSD1 and Nup98-JARID1A [45, 113]. HOXA gene aberrations alone, however, are not sufficient to initiate leukaemogenesis [46, 47], and consequently in about $90 \%$ of NUP98-associated leukaemia an internal tandem duplication of the Flt3 kinase (FLT3-ITD) or overexpression of KRas/NRas has been found, which may account for the uncontrolled proliferation of the leukaemic cells [114-116]. Importantly, HoxA9 expression is not required for myeloid immortalization by NUP98-HOXA9 as shown in HOXA9 $9^{-1-}$ mice [107] and it is low or absent in Nup98 fusion to non-HD partners, for example, Nup98-NSD1, Nup98-RAP1GDS, Nup98TOP1, and Nup98-MLL $[115,117,118]$. Therefore, the entire basis for the impaired differentiation of the haematopoietic precursors upon NUP98 rearrangements remains to be seen.

The potential contribution of the GLFG domain of Nup98 to leukaemogeneis has enjoyed only scant attention, despite the fact that this is the invariable part to all fusion proteins. While Yassin and colleagues found evidence that the Nup98 moiety is also important to disrupt differentiation [119], it is primarily suggested that Nup98 translocation leads to aberrant nucleocytoplasmic transport, mitotic progression, and/or transcription. Aberrant localization of some CRM1 targets in cells expressing Nup98-HoxA9 [61], some mitotic abnormalities due to reduced levels of Rae1 $[120,121]$, and the recruitment of Nup98-HoxA9 and Nup98-PMX1 to kinetochores [98] indicate irregularities in both nucleocytoplasmic transport and mitosis. Whether this is important for leukaemogenesis, however, remains to be seen. Given that Nup98 by itself can bind chromatin [34-36, 91], it is very likely that translocations involving 
TABLE 1: NUP98 fusion partners.

\begin{tabular}{|c|c|c|c|c|c|}
\hline $\begin{array}{l}\text { Nucleoporin } \\
\text { gene }\end{array}$ & Partner gene & Translocation & $\begin{array}{l}\text { Domain or partner } \\
\text { function }\end{array}$ & Disease & Reference \\
\hline \multirow{31}{*}{ NUP98 } & HOXA9 & $\mathrm{t}(7 ; 11)(\mathrm{p} 15 ; \mathrm{p} 15)$ & HD & $\begin{array}{l}\text { AML, MDS, } \\
\text { CML, CMML }\end{array}$ & $\begin{array}{c}{[99,100,104,107} \\
108,112,214]\end{array}$ \\
\hline & HOXA11 & $\mathrm{t}(7 ; 11)(\mathrm{p} 15 ; \mathrm{p} 15)$ & $\mathrm{HD}$ & AML, JMML & {$[215-218]$} \\
\hline & HOXA13 & $\mathrm{t}(7 ; 11)(\mathrm{p} 15 ; \mathrm{p} 15)$ & $\mathrm{HD}$ & AML & {$[215,219]$} \\
\hline & HOXC11 & $\mathrm{t}(11 ; 12)(\mathrm{p} 15 ; \mathrm{q} 13)$ & $\mathrm{HD}$ & AML & {$[220,221]$} \\
\hline & HOXC13 & $\mathrm{t}(11 ; 12)(\mathrm{p} 15 ; \mathrm{q} 13)$ & $\mathrm{HD}$ & AML & {$[222-224]$} \\
\hline & HOXD11 & $\mathrm{t}(2 ; 11)(\mathrm{q} 31 ; \mathrm{p} 15)$ & $\mathrm{HD}$ & AML & {$[223,225]$} \\
\hline & HOXD13 & $\mathrm{t}(2 ; 11)(\mathrm{q} 31 ; \mathrm{p} 15)$ & $\mathrm{HD}$ & AML & [226-229] \\
\hline & HHEX & $\mathrm{t}(10 ; 11)(\mathrm{q} 23 ; \mathrm{p} 15)$ & $\mathrm{HD}$ & AML & [110] \\
\hline & PMX1 & $\mathrm{t}(1 ; 11)(\mathrm{q} 23 ; \mathrm{p} 15)$ & $\mathrm{HD}$ & AML, MDS & {$[230-232]$} \\
\hline & PMX2 & $\mathrm{t}(9 ; 11)(\mathrm{q} 34 ; \mathrm{p} 15)$ & $\mathrm{HD}$ & AML & [233] \\
\hline & POU1F1 & $\mathrm{t}(3 ; 11)(\mathrm{p} 11 ; \mathrm{p} 15)$ & $\mathrm{HD}$ & AML & {$[234]$} \\
\hline & GSX2 & $\mathrm{t}(4 ; 11)(\mathrm{q} 12 ; \mathrm{p} 15)$ & $\mathrm{HD}$ & MDS & {$[235]$} \\
\hline & PHF23 & $\mathrm{t}(11 ; 17)(\mathrm{p} 15 ; \mathrm{p} 13)$ & PHD & AML & [236] \\
\hline & JARID1A & $\mathrm{t}(11 ; 12)(\mathrm{p} 15 ; \mathrm{p} 13)$ & PHD & AML & {$[237,238]$} \\
\hline & NSD1 & $\mathrm{t}(5 ; 11)(\mathrm{q} 35 ; \mathrm{p} 15)$ & PHD & AML, RA & $\begin{array}{c}{[115,116,237,239} \\
244]\end{array}$ \\
\hline & NSD3 & $\mathrm{t}(8 ; 11)(\mathrm{p} 11 ; \mathrm{p} 15)$ & PHD & AML & {$[245,246]$} \\
\hline & MLL & $\operatorname{inv}(11)(p 15 q 23)$ & PHD & AML & [117] \\
\hline & AF10 & $\mathrm{t}(10 ; 11)(\mathrm{p} 12 ; \mathrm{p} 15)$ & AT hook & MDS, CML & {$[235]$} \\
\hline & SETBP1 & $\mathrm{t}(11 ; 18)(\mathrm{p} 15 ; \mathrm{q} 12)$ & AT hook & T-ALL & {$[247]$} \\
\hline & HMGB3 & $\mathrm{t}(X ; 11)(\mathrm{q} 28 ; \mathrm{p} 15)$ & $\begin{array}{l}\text { DNA binding, } \\
\text { bending }\end{array}$ & AML & {$[248]$} \\
\hline & TOP1 & $\mathrm{t}(11 ; 20)(\mathrm{p} 15 ; \mathrm{q} 12)$ & DNA topoisomerase 1 & AML, MDS & {$[249-253]$} \\
\hline & TOP2B & $\mathrm{t}(3 ; 11)(\mathrm{p} 24 ; \mathrm{p} 15)$ & DNA topoisomerase 1 & AML & [254] \\
\hline & DDX10 & $\operatorname{inv}(11)(p 15 q 21-q 23)$ & RNA helicase & $\begin{array}{l}\text { AML, MDS, } \\
\text { CML }\end{array}$ & {$[105,255-258]$} \\
\hline & RAP1GDS1 & $\mathrm{t}(4 ; 11)(\mathrm{q} 21 ; \mathrm{p} 15)$ & RAS signalling & T-ALL & {$[259-261]$} \\
\hline & ADD3 & $\mathrm{t}(10 ; 11)(\mathrm{q} 25 ; \mathrm{p} 15)$ & $\begin{array}{l}\text { Actin-binding, } \\
\text { calmodulin-binding }\end{array}$ & T-ALL & {$[262]$} \\
\hline & ANKRD28 & $\mathrm{t}(3 ; 11)(\mathrm{p} 25 ; \mathrm{p} 15)$ & Ankyrin repeats & AML, MDS & [263] \\
\hline & LEDGF & $\mathrm{t}(9 ; 11)(\mathrm{p} 22 ; \mathrm{p} 15)$ & PWWP domain & AML, CML & {$[223,264-267]$} \\
\hline & IQCG & $\begin{array}{c}\mathrm{t}(3 ; 11)(\mathrm{q} 29 \mathrm{q} 13 ; \mathrm{p} 15) \\
\operatorname{del}(3 \mathrm{q} 29)\end{array}$ & $\begin{array}{l}\text { IQ motif, EF-hand } \\
\text { binding }\end{array}$ & AML, T-ALL & {$[268]$} \\
\hline & RARG & $\mathrm{t}(11 ; 12)(\mathrm{p} 15 ; \mathrm{q} 13)$ & $\begin{array}{l}\text { Nuclear hormone } \\
\text { receptor }\end{array}$ & AML & [269] \\
\hline & CCDC28A & $\mathrm{t}(6 ; 11)(\mathrm{q} 24 ; \mathrm{p} 15)$ & Coiled-coil & AML, T-ALL & {$[270,271]$} \\
\hline & LOC348801 & $\mathrm{t}(3 ; 11)(\mathrm{q} 12 ; \mathrm{p} 15)$ & Coiled-coil & AML & [272] \\
\hline
\end{tabular}

Nup98 lead to misregulation of Nup98 target genes and aberrant haematopoiesis. Moreover, with respect to the poor treatment response of the patients, the Nup98 moiety may be responsible for aberrant DNA damage response and in consequence aberrant apoptosis of the malignant cells [94, 122].

2.3. Nup214. The vertebrate nucleoporin Nup214, also called CAN, is an FG-repeat nucleoporin, which participates in both nuclear import and export [123-126], and is essential for embryonic development in mice [123], and localises to the cytoplasmic face of the NPC [80, 127-129]. Nup214 has been found in three different nucleoporin subcomplexes: together with the nucleoporin Nup88 and the nuclear export factor CRM1 [126, 130-133], as well as in complexes with Nup358 [134] and Nup62 [135], respectively. The Nup214 protein can be divided into three distinct regions (Figure 2(b)): a Nterminal domain containing a $\beta$-propeller [136], a central domain with a predicted coiled-coil region, and a C-terminal flexible and unstructured FG-repeat domain [80, 130]. The N-terminal domain of Nup214 binds to the RNA helicase and mRNA export factor Dbp5/Ddx19 [136-140], whereas the coiled-coil domain is required for binding Nup88 [130, 131]. 
The repeat domain of Nup214 mediates interactions to several nuclear export factors, in particular to the most abundant nuclear export factor CRM1 and also to the export factors for mRNA and t-RNA, TAP/NXF1, and to exportin-t, respectively $[125,126,130,132,141-143]$. The C-terminal domain of Nup214 provides further binding sites for Nup62 [135], as well as for the nuclear import adaptor snurportin 1 [144], Smad2 [145], and tristetraprolin [146]. Nup214 therefore appears to primarily act in nuclear export pathways but appears important in certain nuclear import pathways. In addition, Nup214 is a substrate of the JNK pathway in neurons [147] and target for adenoviruses to promote virus infection $[148,149]$.

\subsection{Chromosomal Translocations Involving NUP214. The} human NUP214 gene locates to chromosome 9q34 and it is a target for chromosomal translocations associated with AML, MDS, acute undifferentiated leukaemia (AUL), and T-ALL $[150,151]$. Four fusion partners have been identified for Nup214 (Table 2): the histone chaperone Set/Taf- $1 \beta$, the chromatin binding factor DEK, the tyrosine kinase Abll, and SQSTM-1 (sequestosome-1), a multifunctional protein that binds ubiquitin and regulates activation of $\mathrm{NF} \kappa \mathrm{B}$ [150-152]. These chromosomal translocations join almost the full-length Set and Dek, respectively, to the C-terminal region of Nup214, containing a portion of the coiled-coil domain and the entire FG domain, the $\mathrm{N}$-terminal half of SQSTM1 to the C-terminal third of Nup214's FG domain, and the N-terminal domain of Nup214 with almost the entire Abll kinase, resulting in SET-NUP214, DEK-NUP214, SQSTM1-NUP214, and NUP214$A B L 1$, respectively (Figure 2(b)). Dek and Set are nuclear proteins and the resulting Nup214 fusion proteins are found in intranuclear foci, while Nup214-Abl1 locates to NPCs [153156].

The mechanisms by which the Nup214 fusions lead to leukaemogenesis are unknown, but SET-NUP214 and DEK-NUP214 show some similarities to Nup98-associated leukaemia. In the SET-NUP214 expressing cell line LOUCY, the HOXA cluster is upregulated and Set-Nup214 binds to promoter regions of HOXA genes, where it interacts with CRM1 and the histone methyltransferase DOT1L, indicating that epigenetic regulation keeps the HOXA locus active [157]. Targeted inhibition of Set-Nup214 abolished the expression of the HOXA genes, inhibited proliferation, and induced differentiation of LOUCY cells. However, this cell line has several other chromosome rearrangements, which may at least partially cooperate with SET-NUP214. SET-NUP214 expression nevertheless consistently inhibits T-cell and myeloid lineage differentiation $[157,158]$, which may result in either AML or T-ALL $[157,159,160]$.

Patients with a DEK-NUP214 translocation have a poor prognosis and a high frequency of FLT3-ITD $[52,161]$. The requirement of a cooperative lesion has also been seen in a SET-NUP214 mice model, as these mice are not leukaemia prone [158]. Expression of Dek-Nup214 coincides with an increased global protein synthesis, which occurs due to increased translation rather than dysregulated transcription [162]. The rise in protein synthesis is restricted to the myeloid lineage and correlates with hyperphosphorylation of the translation initiation factor EIF4E. Expression of Dek-Nup214 cells in myeloid cells caused increased cellular proliferation, which coincided with an upregulation of the mTORC1 activity, without affecting mTORC2 [163]. Augmented proliferation is attributed to a symmetrical decrease of the major cell cycle phases and an upregulation of the mTORC1 protein, which is accompanied by elevated mTORC1 signalling [163]. Inhibition of mTORC1 selectively reverted the Dek-Nup214-induced proliferation.

A third fusion partner of Nup214 is the tyrosine kinase Abl1. NUP214-ABL1 fusions are exclusively associated with TALL and they act as constitutively phosphorylated tyrosine kinase, although with a lower kinase activity than $B C R$ $A B L 1$, the most frequent $A B L 1$ rearrangement $[151,154,155]$. Nup214-Abl1 fusion proteins respond to tyrosine kinase inhibitors, such as imatinib (Glivec), but patients have a poor prognosis $[151,164]$. NUP214-ABL which is weakly transforming in haematopoietic and mouse bone marrow cells, similar to SET-NUP214 and DEK-NUP214, has a multistep pathogenesis and it is associated with Hoxll and HoxllL2 expression, which is frequently found in T-ALL $[151,165]$. Cooperative factors for Nup214-Abll are the SRC kinase LCK as well as the spindle checkpoint protein Mad2L, the nucleoporin Nup155, and the SMC4 subunit of the condensin complex [166].

NUP214-ABL contains the N-terminal part of NUP214 with breakpoints between intron 23 and intron 34 and almost the entire $A B L 1$ gene with breakpoints mostly in intron 1, resulting in fusion proteins of $239-333 \mathrm{kDa}$ (Dek-Nup214 in contrast $\sim 165 \mathrm{kDa}$, Set-Nup214 $\sim 155 \mathrm{kDa}$ ) [150, 151, 159]. The presence of the Nup214 N-terminal domain enables the recruitment of the fusion proteins to NPCs, where they interact with the Nup214-binding partners Nup88 and Nup62. NUP214-ABL1 frequently delete the tumour suppressor genes CDKN2A and CDKN2B [151], while SET-NUP214 have a recurrent deletion of $A B L 1$ (del (9)q31.11q34.13; [167]).

2.5. The Nucleoporin Nup358. Another nucleoporin linked to hematopoietic malignancies is Nup358 (also known as RanBP2), the largest vertebrate nucleoporin [168]. Nup358 is a multidomain protein (Figure 2(b)), which resides at the cytoplasmic filaments of the NPC $[169,170]$. It is involved in numerous cellular processes that range from more general functions in nucleocytoplasmic transport [171-175], mitosis and chromosome segregation [176-179], and cellular signalling due to its E3 SUMO ligase activity [180-184] to more specialized functions, for example, in the translation of a subset of mRNAs encoding secreted and membranebound proteins [185] to tissue-specific functions, particularly in neurons and muscle cells [186-192]. With respect to nucleocytoplasmic transport, Nup358's depletion perturbs the nuclear import of specific cargoes but does not impair nucleocytoplasmic transport in general [169]. Known Nup358dependent nuclear import cargoes are DMAP-1, a DNA methyltransferase 1-associated protein, the putative tumour suppressor DBC-1 (deleted in breast cancer 1), and TERT, the protein component of telomerase $[173,193]$. DMAP-1 and DBC- 1 are directly interacting with the $\mathrm{N}$-terminal region of 
Nup358 in an import receptor-independent manner, whereas importin 7 is mediating the binding of TERT to the zincfinger domain of Nup358 [173, 193]. It is furthermore thought that Nup358 has a critical function in capturing RanGTPimportin $\beta$-complexes at the cytoplasmic filaments of NPCs to allow efficient recycling of importin $\beta$ and in turn importin $\beta$-dependent nuclear import [175]. In this context, it likely promotes the formation of import complexes between DMAP-1 and DBC-1 and importin $\beta$ at the NPC, thereby stimulating their nuclear import [173].

Due to its large size and its diverse domains, manifold functions have been attributed to Nup358. Via its N-terminal, leucine-rich domain (Figure 2(b)), Nup358 is capable of binding interphase microtubules (MTs), which is augmenting MT bundling and stability in $\mathrm{CHO}$ cells, whereas depletion of Nup358 is impairing polarized cell migration and reducing the number of stable MTs [194]. Nup358 association with MTs depends on APC, the adenomatous polyposis coli tumoursuppressor protein, which is a MT plus-end binding protein [195]. APC interacts with both MTs and Nup358 and ectopic expression of its MT-binding domain is sufficient to recruit Nup358 to MT plus ends. The association between Nup358 and APC is important for APC's localization at the cell cortex and for centrosome reorientation during cell migration after wound-scratching [195].

Owing to their central location at the transit routes between the cytoplasm and the cell nucleus, nucleoporins often act as scaffold for proteins for cellular signalling pathways and Nup358 acts as negative regulator of the second messenger cyclic adenosine monophosphate (cAMP) signalling [196]. Epac1, a cAMP-regulated guanine nucleotide exchange factor (GEF) for Rap GTPases, binds directly to the zinc-finger (ZNF) domain of Nup358 (Figure 2(b)) in a phosphorylation-dependent manner. Epacl functions in cellular processes ranging from exocytosis to cell-celljunction formation and cell-extracellular matrix adhesion, and its activity is directly regulated by cAMP [197]. Binding to Nup358 mediates the anchoring of Epac1 to the NE during interphase and in turn inhibits the activity of Epacl towards Rap GTPases. Depletion of Nup358 by RNAi is enhancing Epac1, and hence Nup358 functions as negative regulator of Epacl by establishing an inactive pool of this Rap GEF at NPCs [196].

Nup358 furthermore has tissue-specific functions, in particular in retinal neurons. Nup358 acts specifically as a chaperone for red/green opsin, to which it binds via its Ran-binding domain (RBD) 4 and cyclophilin-like domain (Figure 2(b)) in Drosophila, human, and bovine cells [198, 199]. In mice, Nup358 acts as a chaperone for the mitochondrial metallochaperone Cox11 [200]. Nup358 and Cox11 are copurified from retina extracts and colocalize to mitochondria in several classes of neurons, including photosensory neurons and neurons of the central nervous system (CNS). Nup358 is suppressing the inhibitory activity of Cox11 over hexokinase I (HKI), the major regulator of glycolysis [200]. Haploinsufficiency in Nup358 causes the delocalization of mitochondria in the photosensory neurons and defects in glucose clearance and the electrophysiological response of photosensory and postreceptoral neurons, the latter likely due to a pronounced decrease of HKI and ATP levels in the CNS [200, 201]. Nup358 further associates with kinesin KIF5B and KIF5C in the cytoplasm via its kinesin-binding domain and the Ran-binding domains 2 and 3 (Figure 2(b)) $[148,189,202]$. Nup358 binds leucine-rich heptad repeats in the C-terminal coiled-coil domain of the kinesin heavy chain $[188,189,201,202]$. In the presence of MTs and ATP, binding of Nup358 enhances the low intrinsic ATPase activity of KIF5B. A disruption of the interaction between Nup358 and the KIF5s results in perinuclear clustering of mitochondria, deficits in the mitochondria membrane potential, and cell shrinkage, further supporting the role of Nup358 in mitochondria transport and function [201].

By a mechanism that is not understood, haploinsufficiency of Nup358 in aged mice safeguards neurons against light-induced oxidative stress $[186,187]$. Neurodegeneration of photoreceptors by apoptosis is induced by prolonged light exposure, and aged Nup358 $8^{+/-}$mice have suppressed apoptosis and reduced membrane dysgenesis in central retina regions when exposed to light stress [187]. The reduced lightinduced oxidative stress and the suppression of apoptosis in haploinsufficient Nup358 cells appears to be due to reduced levels of free fatty acids, the upregulation of the orphan transmembrane tyrosine kinase receptor ErbB2, and the suppression of ubiquitylation [186, 187]. Together these studies point to a determinant role for Nup358 in glucose, energy, and lipid homeostasis in neurons of the CNS and the retina and implicate Nup358 (and its binding partners) as key player in neuropathic and neurodegenerative diseases [200].

2.6. Chromosomal Translocations Involving NUP358. Nup358 is located on chromosome $2 \mathrm{p} 12$ and is found in chromosomal translocations with the fibroblasts growth factor receptor 1 (FGFR1), a tyrosine kinase receptor, and the anaplastic lymphoma kinase (ALK) (Table 2). Nup358-FGFR1 fusion results in myeloproliferative/myelodysplastic syndrome [203]. Three fusions of NUP358 exon 20 with FGFR1 exon 9 have been identified, which preserves the LRD of Nup358 and the two tyrosine kinase domains of FGFR1. Nup358-FGFR1 is not further characterized, but FGFR1 is known to be fused to different recurrent gene partners and its translocation typically leads to its constitutive activation. FGFR1-associated malignancies are rare, aggressive myeloproliferative syndromes that rapidly progress into AML and are associated with a bad prognosis [203].

The NUP358-ALK fusion is associated with several human malignancies ranging from inflammatory myofibroblastic tumours (IMT) to large B cell lymphoma and MDS/AML and is associated with a poor patient prognosis [204-211]. ALK is a receptor tyrosine kinase and hyperactivated in the fusions, which may coincide with the hyperphosphorylation of cooperative factors, such as STAT3 [205]. The fusion points are consistently composed of exon 19 of NUP358 and exon 20 of ALK, which maintains the LRD of Nup358 and the tyrosine kinase domain of Alk and results in a fusion protein of 1430 amino acids that resides at the nuclear membrane [206-208]. The molecular bases for the diseases are unknown, but the expression of Nup358 
TABLE 2: NUP214 and NUP358 fusion partner.

\begin{tabular}{|c|c|c|c|c|c|}
\hline Nucleoporin gene & Partner gene & Translocation & Partner function & Disease & Reference \\
\hline \multirow{4}{*}{ NUP214 } & SET & $\operatorname{del}(9)(\mathrm{q} 34)$ & $\begin{array}{c}\text { Apoptosis, cell cyle, } \\
\text { migration, nucleosome } \\
\text { assembly, inhibitor of PP2A }\end{array}$ & T-ALL, AML & $\begin{array}{l}{[150,153,156-158} \\
160,167,273,274]\end{array}$ \\
\hline & DEK & $\mathrm{t}(6 ; 9)(\mathrm{p} 22 ; \mathrm{q} 34)$ & $\begin{array}{l}\text { DNA-binding, } \\
\text { transcription }\end{array}$ & AML, MDS & $\begin{array}{l}{[150,156,159,161} \\
162,274,275]\end{array}$ \\
\hline & ABL1 & $\operatorname{Amp}(9 q 34)$ & Tyrosine kinase & T-ALL & $\begin{array}{c}{[151,154,155,158,} \\
164-166,276-278]\end{array}$ \\
\hline & SQSTM1 & & $\mathrm{NF} \kappa \mathrm{B}$ activation & T-ALL & {$[152]$} \\
\hline \multirow{2}{*}{ NUP358 } & ALK & inv2(p23; q13) & Kinase & AML, MDS, IMT & [204-211] \\
\hline & FGFR1 & $\mathrm{t}(2 ; 8)(\mathrm{q} 12 ; \mathrm{p} 11)$ & Tyrosine receptor kinase & MDS & [203] \\
\hline
\end{tabular}

chimeras commonly lead to the presence of large nucleoli. Moreover, IMT tumours are massive and the incidence for IMT is significantly higher in male with a male to female ratio of $10: 1[205,209]$.

\section{Conclusion}

Three nucleoporins, Nup98, Nup214, and Nup358, are targets for rare but recurrent chromosomal translocations, which by the majority lead to AML. NUP98 and NUP214 rearrangements share some common characteristics, such as HOXA activation and cooperation with the FLT3-ITD kinase, which may account for the impaired differentiation of the haematopoietic precursor cells and their uncontrolled proliferation. NUP214 and NUP358 fusion partners are on the other hand often kinases, which become constitutively activated and may stimulate proliferation. The basis for impaired differentiation to myeloid cells has remained elusive. Commonly malignancies associated with Nup98, Nup214, and Nup358 come along with a poor prognosis for the patients and a poor treatment outcome. As Nup98, Nup214, and Nup358 are all somewhat important for protein and/or mRNA export, it will be interesting to see if their rearrangements lead to similar defects in nuclear export, which may account for the marked similarities in the clinical features in the hematopoietic malignancies associated with these three nucleoporins. Of particular interest in this context might be their link to the nuclear export receptor CRM1, which appears to play an important role in the aetiology of AML. CRM1 is mediating the nuclear export of tumour suppressor proteins and cell cycle regulators, such as p53 and nucleophosmin (NPM) [212]. Mutations in NPM account for about one-third of AML cases in adults and the mutations lead to an enhanced nuclear export of NPM. Novel, selective CRM1 inhibitors are currently tested in vitro and in vivo in preclinical and clinical trials to treat NPM-related AML [213]. These CRM1 inhibitors are inhibiting proliferation and inducing cell-cycle arrest, apoptosis, and differentiation, they cause decreased CRM1 protein levels and accumulation of CRM1 targets (including p53 and NPM) in the nucleus, and they also cause a downregulation of FLT3 and FLT3-ITD [213]. These promising results indicate that CRM1 might be a therapeutic target to treat AML and it will be highly interesting to see whether or not this also holds true for nucleoporin-associated AML.

\section{Conflict of Interests}

The author declares that there is no conflict of interests regarding the publication of this paper.

\section{References}

[1] S. Wälde and R. H. Kehlenbach, "The part and the whole: functions of nucleoporins in nucleocytoplasmic transport," Trends in Cell Biology, vol. 20, no. 8, pp. 461-469, 2010.

[2] S. R. Wente and M. P. Rout, "The nuclear pore complex and nuclear transport," Cold Spring Harbor Perspectives in Biology, vol. 2, no. 10, Article ID a000562, 2010.

[3] J. M. Cronshaw, A. N. Krutchinsky, W. Zhang, B. T. Chait, and M. L. J. Matunis, "Proteomic analysis of the mammalian nuclear pore complex," Journal of Cell Biology, vol. 158, no. 5, pp. 915-927, 2002.

[4] A. Ori, N. Banterle, M. Iskar et al., "Cell type-specific nuclear pores: a case in point for context-dependent stoichiometry of molecular machines," Molecular Systems Biology, vol. 9, article 648, 2013.

[5] M. P. Rout, J. D. Aitchison, A. Suprapto, K. Hjertaas, Y. Zhao, and B. T. Chait, "The yeast nuclear pore complex: composition, architecture, transport mechanism," Journal of Cell Biology, vol. 148, no. 4, pp. 635-651, 2000.

[6] B. Fahrenkrog and U. Aebi, "The nuclear pore complex: nucleocytoplasmic transport and beyond," Nature Reviews Molecular Cell Biology, vol. 4, no. 10, pp. 757-766, 2003.

[7] R. Y. H. Lim, U. Aebi, and B. Fahrenkrog, "Towards reconciling structure and function in the nuclear pore complex," Histochemistry and Cell Biology, vol. 129, no. 2, pp. 105-116, 2008.

[8] M. A. D’Angelo and M. W. Hetzer, "Structure, dynamics and function of nuclear pore complexes," Trends in Cell Biology, vol. 18, no. 10, pp. 456-466, 2008.

[9] T. Maimon, N. Elad, I. Dahan, and O. Medalia, "The human nuclear pore complex as revealed by cryo-electron tomography," Structure, vol. 20, no. 6, pp. 998-1006, 2012.

[10] K. H. Bui, A. von Appen, A. L. Diguilio et al., "Integrated structural analysis of the human nuclear pore complex scaffold," Cell, vol. 155, pp. 1233-1243, 2013. 
[11] F. Alber, S. Dokudovskaya, L. M. Veenhoff et al., "The molecular architecture of the nuclear pore complex," Nature, vol. 450, no. 7170, pp. 695-701, 2007.

[12] R. Reichelt, A. Holzenburg, E. L. Buhle Jr., M. Jarnik, A. Engel, and U. Aebi, "Correlation between structure and mass distribution of the nuclear pore complex and of distinct pore complex components," Journal of Cell Biology, vol. 110, no. 4, pp. 883-894, 1990.

[13] M. Capelson, C. Doucet, and M. W. Hetzer, "Nuclear pore complexes: guardians of the nuclear genome," Cold Spring Harbor Symposia on Quantitative Biology, vol. 75, pp. 585-597, 2011.

[14] D. Stoffler, B. Feja, B. Fahrenkrog, J. Walz, D. Typke, and U. Aebi, "Cryo-electron tomography provides novel insights into nuclear pore architecture: implications for nucleocytoplasmic transport," Journal of Molecular Biology, vol. 328, no. 1, pp. 119-130, 2003.

[15] M. Beck, F. Förster, M. Ecke et al., "Nuclear pore complex structure and dynamics revealed by cryoelectron tomography," Science, vol. 306, no. 5700, pp. 1387-1390, 2004.

[16] B. Fahrenkrog, E. C. Hurt, U. Aebi, and N. Panté, "Molecular architecture of the yeast nuclear pore complex: localization of Nsplp subcomplexes," Journal of Cell Biology, vol. 143, no. 3, pp. 577-588, 1998.

[17] J. Fiserova, E. Kiseleva, and M. W. Goldberg, "Nuclear envelope and nuclear pore complex structure and organization in tobacco BY-2 cells," Plant Journal, vol. 59, no. 2, pp. 243-255, 2009.

[18] E. Kiseleva, T. D. Allen, S. Rutherford, M. Bucci, S. R. Wente, and M. W. Goldberg, "Yeast nuclear pore complexes have a cytoplasmic ring and internal filaments," Journal of Structural Biology, vol. 145, no. 3, pp. 272-288, 2004.

[19] D. Frenkiel-Krispin, B. Maco, U. Aebi, and O. Medalia, "Structural analysis of a metazoan nuclear pore complex reveals a fused concentric ring architecture," Journal of Molecular Biology, vol. 395, no. 3, pp. 578-586, 2009.

[20] M. Beck, V. Lǔí, F. Förster, W. Baumeister, and O. Medalia, "Snapshots of nuclear pore complexes in action captured by cryo-electron tomography," Nature, vol. 449, no. 7162, pp. 611-615, 2007.

[21] N. Panté and M. Kann, "Nuclear pore complex is able to transport macromolecules with diameters of $\sim 39 \mathrm{~nm}$," Molecular Biology of the Cell, vol. 13, no. 2, pp. 425-434, 2002.

[22] K. Enss, T. Danker, A. Schlune, I. Buchholz, and H. Oberleithner, "Passive transport of macromolecules through xenopus laevis nuclear envelope," Journal of Membrane Biology, vol. 196, no. 3, pp. 147-155, 2003.

[23] O. Keminer and R. Peters, "Permeability of single nuclear pores," Biophysical Journal, vol. 77, no. 1, pp. 217-228, 1999.

[24] D. Mohr, S. Frey, T. Fischer, T. Güttler, and D. Görlich, "Characterisation of the passive permeability barrier of nuclear pore complexes," The EMBO Journal, vol. 28, no. 17, pp. 2541-2553, 2009.

[25] N. Elad, T. Maimon, D. Frenkiel-Krispin, R. Y. Lim, and O. Medalia, "Structural analysis of the nuclear pore complex by integrated approaches," Current Opinion in Structural Biology, vol. 19, no. 2, pp. 226-232, 2009.

[26] M. Raices and M. A. D’Angelo, “Nuclear pore complex composition: a new regulator of tissue-specific and developmental functions," Nature Reviews Molecular Cell Biology, vol. 13, no. 11, pp. 687-699, 2012.

[27] D. Görlich and U. Kutay, "Transport between the cell nucleus and the cytoplasm," Annual Review of Cell and Developmental Biology, vol. 15, pp. 607-660, 1999.
[28] T. U. Schwartz, "Modularity within the architecture of the nuclear pore complex," Current Opinion in Structural Biology, vol. 15, no. 2, pp. 221-226, 2005.

[29] D. Devos, S. Dokudovskaya, R. Williams et al., "Simple fold composition and modular architecture of the nuclear pore complex," Proceedings of the National Academy of Sciences of the United States of America, vol. 103, no. 7, pp. 2172-2177, 2006.

[30] A. Szymborska, A. de Marco, N. Daigle, V. C. Cordes, J. A. Briggs, and J. Ellenberg, "Nuclear pore scaffold structure analyzed by super-resolution microscopy and particle averaging," Science, vol. 341, pp. 655-658, 2013.

[31] K. Thierbach, A. von Appen, M. Thoms, M. Beck, D. Flemming, and E. Hurt, "Protein interfaces of the conserved Nup84 complex from Chaetomium thermophilum shown by crosslinking mass spectrometry and electron microscopy," Structure, vol. 21, pp. 1672-1682, 2013.

[32] B. Fahrenkrog, J. Köser, and U. Aebi, "The nuclear pore complex: a jack of all trades?" Trends in Biochemical Sciences, vol. 29, no. 4, pp. 175-182, 2004.

[33] M. Capelson and M. W. Hetzer, "The role of nuclear pores in gene regulation, development and disease," EMBO Reports, vol. 10, no. 7, pp. 697-705, 2009.

[34] T. M. Franks and M. W. Hetzer, "The role of Nup98 in transcription regulation in healthy and diseased cells," Trends in Cell Biology, vol. 23, no. 3, pp. 112-117, 2013.

[35] Y. Liang, T. M. Franks, M. C. Marchetto, F. H. Gage, and M. W. Hetzer, "Dynamic association of NUP98 with the human genome," PLoS Genetics, vol. 9, no. 2, Article ID e1003308, 2013.

[36] B. Kalverda, H. Pickersgill, V. V. Shloma, and M. Fornerod, "Nucleoporins directly stimulate expression of developmental and cell-cycle genes inside the nucleoplasm," Cell, vol. 140, no. 3, pp. 360-371, 2010.

[37] S. Mendjan, M. Taipale, J. Kind et al., "Nuclear pore components are involved in the transcriptional regulation of dosage compensation in Drosophila," Molecular Cell, vol. 21, no. 6, pp. 811-823, 2006.

[38] J. M. Vaquerizas, R. Suyama, J. Kind, K. Miura, N. M. Luscombe, and A. Akhtar, "Nuclear pore proteins Nup153 and megator define transcriptionally active regions in the Drosophila genome," PLoS Genetics, vol. 6, no. 2, Article ID e1000846, 2010.

[39] G. Chatel and B. Fahrenkrog, "Nucleoporins: leaving the nuclear pore complex for a successful mitosis," Cellular Signalling, vol. 23, no. 10, pp. 1555-1562, 2011.

[40] R. Wozniak, B. Burke, and V. Doye, "Nuclear transport and the mitotic apparatus: an evolving relationship," Cellular and Molecular Life Sciences, vol. 67, no. 13, pp. 2215-2230, 2010.

[41] H. Nakano, W. Wang, C. Hashizume, T. Funasaka, H. Sato, and R. W. Wong, "Unexpected role of nucleoporins in coordination of cell cycle progression," Cell Cycle, vol. 10, no. 3, pp. 425-433, 2011.

[42] C. Plass, C. Oakes, W. Blum, and G. Marcucci, "Epigenetics in acute myeloid leukemia," Seminars in Oncology, vol. 35, no. 4, pp. 378-387, 2008.

[43] R. A. Alharbi, R. Pettengell, H. S. Pandha, and R. Morgan, "The role of HOX genes in normal hematopoiesis and acute leukemia," Leukemia, vol. 27, no. 5, pp. 1000-1008, 2013.

[44] D. G. Grier, A. Thompson, A. Kwasniewska, G. J. McGonigle, H. L. Halliday, and T. R. Lappin, "The pathophysiology of HOX genes and their role in cancer," Journal of Pathology, vol. 205, no. 2, pp. 154-171, 2005. 
[45] G. G. Wang, L. Cai, M. P. Pasillas, and M. P. Kamps, "NUP98NSD1 links H3K36 methylation to Hox-A gene activation and leukaemogenesis," Nature Cell Biology, vol. 9, no. 7, pp. 804-812, 2007.

[46] A. R. Kumar, W. A. Hudson, W. Chen, R. Nishiuchi, Q. Yao, and J. H. Kersey, "Hoxa9 influences the phenotype but not the incidence of Mll-AF9 fusion gene leukemia," Blood, vol. 103, no. 5, pp. 1823-1828, 2004.

[47] H. Liu, E. H.-Y. Cheng, and J. J.-D. Hsieh, "MLL fusions: pathways to leukemia," Cancer Biology and Therapy, vol. 8, no. 13, pp. 1204-1211, 2009.

[48] M. Faretta, L. di Croce, and P. G. Pelicci, "Effects of the acute myeloid leukemia-associated fusion proteins on nuclear architecture," Seminars in Hematology, vol. 38, no. 1, pp. 42-53, 2001.

[49] J. Chen, O. Odenike, and J. D. Rowley, "Leukaemogenesis: more than mutant genes," Nature Reviews Cancer, vol. 10, no. 1, pp. 23-36, 2010.

[50] R. P. Hasserjian, "Acute myeloid leukemia: advances in diagnosis and classification," International Journal of Laboratory Hematology, vol. 35, no. 3, pp. 358-366, 2013.

[51] S. M. Gough, C. I. Slape, and P. D. Aplan, "NUP98 gene fusions and hematopoietic malignancies: common themes and new biologic insights," Blood, vol. 118, no. 24, pp. 6247-6257, 2011.

[52] L. Garçon, M. Libura, E. Delabesse et al., "DEK-CAN molecular monitoring of myeloid malignancies could aid therapeutic stratification," Leukemia, vol. 19, no. 8, pp. 1338-1344, 2005.

[53] M. Andreeff, V. Ruvolo, S. Gadgil et al., "HOX expression patterns identify a common signature for favorable AML," Leukemia, vol. 22, no. 11, pp. 2041-2047, 2008.

[54] E. R. Griffis, N. Altan, J. Lippincott-Schwartz, and M. A. Powers, "Nup98 is a mobile nucleoporin with transcription-dependent dynamics," Molecular Biology of the Cell, vol. 13, no. 4, pp. 1282-1297, 2002.

[55] E. R. Griffis, B. Craige, C. Dimaano, K. S. Ullman, and M. A. Powers, "Distinct functional domains within nucleoporins Nup153 and Nup98 mediate transcription-dependent mobility," Molecular Biology of the Cell, vol. 15, pp. 1991-2002, 2004.

[56] B. M. A. Fontoura, G. Blobel, and M. J. Matunis, "A conserved biogenesis pathway for nucleoporins: proteolytic processing of a 186-kilodalton precursor generates Nup98 and the novel nucleoporin, Nup96," Journal of Cell Biology, vol. 144, no. 6, pp. 1097-1112, 1999.

[57] M. Iwamoto, H. Asakawa, Y. Hiraoka, and T. Haraguchi, "Nucleoporin Nup98: a gatekeeper in the eukaryotic kingdoms," Genes to Cells, vol. 15, no. 7, pp. 661-669, 2010.

[58] A. E. Hodel, M. R. Hodel, E. R. Griffis et al., "The threedimensional structure of the autoproteolytic, nuclear poretargeting domain of the human nucleoporin Nup98," Molecular Cell, vol. 10, no. 2, pp. 347-358, 2002.

[59] J. S. Rosenblum and G. Blobel, "Autoproteolysis in nucleoporin biogenesis," Proceedings of the National Academy of Sciences of the United States of America, vol. 96, no. 20, pp. 11370-11375, 1999.

[60] M. Oka, M. Asally, Y. Yasuda, Y. Ogawa, T. Tachibana, and Y. Yoneda, "The mobile FG nucleoporin Nup98 is a cofactor for Crml-dependent protein export," Molecular Biology of the Cell, vol. 21, no. 11, pp. 1885-1896, 2010.

[61] A. Takeda, N. J. Sarma, A. M. Abdul-Nabi, and N. R. Yaseen, "Inhibition of CRM1-mediated nuclear export of transcription factors by leukemogenic NUP98 fusion proteins," Journal of Biological Chemistry, vol. 285, no. 21, pp. 16248-16257, 2010.
[62] M. B. Blevins, A. M. Smith, E. M. Phillips, and M. A. Powers, "Complex formation among the RNA export proteins Nup98, Rae1/Gle2, and TAP," Journal of Biological Chemistry, vol. 278, no. 23, pp. 20979-20988, 2003.

[63] A. Bachi, I. C. Braun, J. P. Rodrigues et al., "The C-terminal domain of TAP interacts with the nuclear pore complex and promotes export of specific CTE-bearing RNA substrates," $R N A$, vol. 6, no. 1, pp. 136-158, 2000.

[64] Y. Ren, H. S. Seo, G. Blobel, and A. Hoelz, "Structural and functional analysis of the interaction between the nucleoporin Nup98 and the mRNA export factor Rael," Proceedings of the National Academy of Sciences of the United States of America, vol. 107, no. 23, pp. 10406-10411, 2010.

[65] C. E. J. Pritchard, M. Fornerod, L. H. Kasper, and J. M. A. van Deursen, "RAE1 is a shuttling mRNA export factor that binds to a GLEBS-like NUP98 motif at the nuclear pore complex through multiple domains," Journal of Cell Biology, vol. 145, no. 2, pp. 237-253, 1999.

[66] L. H. Kasper, P. K. Brindle, C. A. Schnabel, C. E. J. Pritchard, M. L. Cleary, and J. M. A. van Deursen, "CREB binding protein interacts with nucleoporin-specific FG repeats that activate transcription and mediate NUP98-HOXA9 oncogenicity," Molecular and Cellular Biology, vol. 19, no. 1, pp. 764-776, 1999.

[67] E. R. Griffis, S. Xu, and M. A. Powers, "Nup98 localizes to both nuclear and cytoplasmic sides of the nuclear pore and binds to two distinct nucleoporin subcomplexes," Molecular Biology of the Cell, vol. 14, no. 2, pp. 600-610, 2003.

[68] V. E. Gould, A. Orucevic, H. Zentgraf, P. Gattuso, N. Martinez, and A. Alonso, "Nup88 (karyoporin) in human malignant neoplasms and dysplasias: correlations of immunostaining of tissue sections, cytologic smears, and immunoblot analysis," Human Pathology, vol. 33, no. 5, pp. 536-544, 2002.

[69] S. Xu and M. A. Powers, "Nuclear pore proteins and cancer," Seminars in Cell and Developmental Biology, vol. 20, no. 5, pp. 620-630, 2009.

[70] K. S. Ullman, S. Shah, M. A. Powers, and D. J. Forbes, "The nucleoporin Nup153 plays a critical role in multiple types of nuclear export," Molecular Biology of the Cell, vol. 10, no. 3, pp. 649-664, 1999.

[71] E. Voronina and G. Seydoux, "The C. elegans homolog of nucleoporin Nup98 is required for the integrity and function of germline P granules," Development, vol. 137, no. 9, pp. 1441-1450, 2010.

[72] S. Krull, J. Thyberg, B. Björkroth, H. R. Rackwitz, and V. C. Cordes, "Nucleoporins as components of the nuclear pore complex core structure and Tpr as the architectural element of the nuclear basket," Molecular Biology of the Cell, vol. 15, no. 9, pp. 4261-4277, 2004.

[73] G. Chatel, S. H. Desai, A. L. Mattheyses, M. A. Powers, and B. Fahrenkrog, "Domain topology of nucleoporin Nup98 within the nuclear pore complex," Journal of Structural Biology, vol. 177, no. 1, pp. 81-89, 2012.

[74] D. P. Denning, S. S. Patel, V. Uversky, A. L. Fink, and M. Rexach, "Disorder in the nuclear pore complex: the FG repeat regions of nucleoporins are natively unfolded," Proceedings of the National Academy of Sciences of the United States of America, vol. 100, no. 5, pp. 2450-2455, 2003.

[75] D. P. Denning, V. Uversky, S. S. Patel, A. L. Fink, and M. Rexach, "The Saccharomyces cerevisiae nucleoporin Nup2p is a natively unfolded protein," Journal of Biological Chemistry, vol. 277, no. 36, pp. 33447-33455, 2002. 
[76] S. S. Patel, B. J. Belmont, J. M. Sante, and M. F. Rexach, "Natively unfolded nucleoporins gate protein diffusion across the nuclear pore complex," Cell, vol. 129, no. 1, pp. 83-96, 2007.

[77] V. V. Krishnan, E. Y. Lau, J. Yamada et al., "Intramolecular cohesion of coils mediated by phenylalanine-glycine motifs in the natively unfolded domain of a nucleoporin," PLoS Computational Biology, vol. 4, no. 8, Article ID e1000145, 2008.

[78] J. Yamada, J. L. Phillips, S. Patel et al., "A bimodal distribution of two distinct categories of intrinsically disordered structures with separate functions in FG nucleoporins," Molecular and Cellular Proteomics, vol. 9, no. 10, pp. 2205-2224, 2010.

[79] B. Fahrenkrog, B. Maco, A. M. Fager et al., "Domain-specific antibodies reveal multiple-site topology of Nup153 within the nuclear pore complex," Journal of Structural Biology, vol. 140, no. 1-3, pp. 254-267, 2002.

[80] S. M. Paulillo, E. M. Phillips, J. Köser et al., "Nucleoporin domain topology is linked to the transport status of the nuclear pore complex," Journal of Molecular Biology, vol. 351, no. 4, pp. 784-798, 2005.

[81] S. M. Paulillo, M. A. Powers, K. S. Ullman, and B. Fahrenkrog, "Changes in nucleoporin domain topology in response to chemical effectors," Journal of Molecular Biology, vol. 363, no. 1, pp. 39-50, 2006.

[82] K. Schwarz-Herion, B. Maco, U. Sauder, and B. Fahrenkrog, "Domain topology of the p62 complex within the 3-D architecture of the nuclear pore complex," Journal of Molecular Biology, vol. 370, no. 4, pp. 796-806, 2007.

[83] X. Wu, L. H. Kasper, R. T. Mantcheva, G. T. Mantchev, M. J. Springett, and J. M. A. van Deursen, "Disruption of the FG nucleoporin Nup98 causes selective changes in nuclear pore complex stoichiometry and function," Proceedings of the National Academy of Sciences of the United States of America, vol. 98, no. 6, pp. 3191-3196, 2001.

[84] M. A. Powers, D. J. Forbes, J. E. Dahlberg, and E. Lund, "The vertebrate GLFG nucleoporin, Nup98, is an essential component of multiple RNA export pathways," The Journal of Cell Biology, vol. 136, pp. 241-250, 1997.

[85] M. A. Powers, C. Macaulay, F. R. Masiarz, and D. J. Forbes, "Reconstituted nuclei depleted of a vertebrate GLFG nuclear pore protein, p97, import but are defective in nuclear growth and replication," Journal of Cell Biology, vol. 128, no. 5, pp. 721-736, 1995.

[86] B. M. A. Fontoura, G. Blobel, and N. R. Yaseen, "The nucleoporin Nup98 is a site for GDP/GTP exchange on ran and termination of karyopherin $\beta 2$-mediated nuclear import," Journal of Biological Chemistry, vol. 275, no. 40, pp. 31289-31296, 2000.

[87] A. Radu, M. S. Moore, and G. Blobel, "The peptide repeat domain of nucleoporin Nup98 functions as a docking site in transport across the nuclear pore complex," Cell, vol. 81, no. 2, pp. 215-222, 1995.

[88] A. S. Zolotukhin and B. K. Felber, "Nucleoporins Nup98 and Nup214 participate in nuclear export of human immunodeficiency virus type 1 Rev," Journal of Virology, vol. 73, no. 1, pp. 120-127, 1999.

[89] C. P. C. de Souza, K. P. Horn, K. Masker, and S. A. Osmani, “The SONBNUP98 nucleoporin interacts with the NIMA Kinase in aspergillus nidulans," Genetics, vol. 165, no. 3, pp. 1071-1081, 2003.

[90] B. B. Hülsmann, A. A. Labokha, and D. Görlich, "The permeability of reconstituted nuclear pores provides direct evidence for the selective phase model," Cell, vol. 150, no. 4, pp. 738-751, 2012.
[91] M. Capelson, Y. Liang, R. Schulte, W. Mair, U. Wagner, and M. W. Hetzer, "Chromatin-bound nuclear pore components regulate gene expression in higher eukaryotes," Cell, vol. 140, no. 3, pp. 372-383, 2010.

[92] W. H. Light, J. Freaney, V. Sood et al., "A conserved role for human Nup98 in altering chromatin structure and promoting epigenetic transcriptional memory," PLoS Biology, vol. 11, no. 3, Article ID e1001524, 2013.

[93] S. Singer, R. Zhao, A. M. Barsotti et al., "Nuclear pore component Nup98 is a potential tumor suppressor and regulates posttranscriptional expression of select p53 target genes," Molecular Cell, vol. 48, no. 5, pp. 799-810, 2012.

[94] C. P. C. de Souza, S. B. Hashmi, K. P. Horn, and S. A. Osmani, "A point mutation in the Aspergillus nidulans sonBNup98 nuclear pore complex gene causes conditional DNA damage sensitivity," Genetics, vol. 174, no. 4, pp. 1881-1893, 2006.

[95] M. K. Cross and M. A. Powers, "Nup98 regulates bipolar spindle assembly through association with microtubules and opposition of MCAK," Molecular Biology of the Cell, vol. 22, no. 5, pp. 661-672, 2011.

[96] K. B. Jeganathan, D. J. Baker, and J. M. van Deursen, "Securin associates with APCCdh1 in prometaphase but its destruction is delayed by Rael and Nup98 until the metaphase/anaphase transition," Cell Cycle, vol. 5, no. 4, pp. 366-370, 2006.

[97] K. B. Jeganathan, L. Malureanu, and J. M. van Deursen, "The Rael-Nup98 complex prevents aneuploidy by inhibiting securin degradation," Nature, vol. 438, no. 7070, pp. 1036-1039, 2005.

[98] S. Xu and M. A. Powers, "Nup98-homeodomain fusions interact with endogenous Nup98 during interphase and localize to kinetochores and chromosome arms during mitosis," Molecular Biology of the Cell, vol. 21, no. 9, pp. 1585-1596, 2010.

[99] J. Borrow, A. M. Shearman, V. P. Stanton Jr. et al., "The $\mathrm{t}(7 ; 11)(\mathrm{p} 15 ; \mathrm{p} 15)$ translocation in acute myeloid leukaemia fuses the genes for nucleoporin NUP98 and class I homeoprotein HOXA9," Nature Genetics, vol. 12, pp. 159-167, 1996.

[100] T. Nakamura, D. A. Largaespada, M. P. Lee et al., "Fusion of the nucleoporin gene NUP98 to HOXA9 by the chromosome translocation $\mathrm{t}(7 ; 11)(\mathrm{p} 15 ; \mathrm{p} 15)$ in human myeloid leukaemia," Nature Genetics, vol. 12, pp. 154-158, 1996.

[101] D. H. Lam and P. D. Aplan, "NUP98 gene fusions in hematologic malignancies," Leukemia, vol. 15, no. 11, pp. 1689-1695, 2001.

[102] J. M. Scandura, P. Boccuni, J. Cammenga, and S. D. Nimer, "Transcription factor fusions in acute leukemia: variations on a theme," Oncogene, vol. 21, pp. 3422-3444, 2002.

[103] M. A. S. Moore, K. Y. Chung, M. Plasilova et al., "NUP98 dysregulation in myeloid leukemogenesis," Annals of the New York Academy of Sciences, vol. 1106, pp. 114-142, 2007.

[104] W. C. Chou, C. Y. Chen, H. A. Hou et al., "Acute myeloid leukemia bearing $\mathrm{t}(7 ; 11)(\mathrm{p} 15 ; \mathrm{p} 15)$ is a distinct cytogenetic entity with poor outcome and a distinct mutation profile: comparative analysis of 493 adult patients," Leukemia, vol. 23, pp. 1303-1310, 2009.

[105] P. Gorello, V. Nofrini, L. Brandimarte et al., "Inv(11)(p15q22)/ NUP98-DDX10 fusion and isoforms in a new case of de novo acute myeloid leukemia," Cancer Genetics, vol. 206, no. 3, pp. 92-96, 2013.

[106] N. Shah and S. Sukumar, "The Hox genes and their roles in oncogenesis," Nature Reviews Cancer, vol. 10, no. 5, pp. 361-371, 2010.

[107] K. R. Calvo, D. B. Sykes, M. P. Pasillas, and M. P. Kamps, "Nup98-Hoxa9 immortalizes myeloid progenitors, enforces 
expression of Hoxa9, Hoxa7 and Meisl, and alters cytokinespecific responses in a manner similar to that induced by retroviral co-expression of Hoxa9 and Meisl," Oncogene, vol. 21, no. 27, pp. 4247-4256, 2002.

[108] K. Y. Chung, G. Morrone, J. J. Schuringa et al., "Enforced expression of NUP98-HOXA9 in human CD34+ cells enhances stem cell proliferation," Cancer Research, vol. 66, no. 24, pp. 11781-11791, 2006.

[109] K. Hirose, C. Abramovich, B. Argiropoulos, and R. K. Humphries, "Leukemogenic properties of NUP98-PMX1 are linked to NUP98 and homeodomain sequence functions but not to binding properties of PMX1 to serum response factor," Oncogene, vol. 27, no. 46, pp. 6056-6067, 2008.

[110] D. Jankovic, P. Gorello, T. Liu et al., "Leukemogenic mechanisms and targets of a NUP98/HHEX fusion in acute myeloid leukemia," Blood, vol. 111, no. 12, pp. 5672-5682, 2008.

[111] L. Palmqvist, N. Pineault, C. Wasslavik, and R. K. Humphries, "Candidate genes for expansion and transformation of hematopoietic stem cells by NUP98-HOX fusion genes," PLoS ONE, vol. 2, no. 8, article e768, 2007.

[112] A. Takeda, C. Goolsby, and N. R. Yaseen, "NUP98-HOXA9 induces long-term proliferation and blocks differentiation of primary human CD34+ hematopoietic cells," Cancer Research, vol. 66, no. 13, pp. 6628-6637, 2006.

[113] G. G. Wang, J. Song, Z. Wang et al., "Haematopoietic malignancies caused by dysregulation of a chromatin-binding PHD finger," Nature, vol. 459, no. 7248, pp. 847-851, 2009.

[114] T. Taketani, T. Taki, T. Nakamura et al., "High frequencies of simultaneous FLT3-ITD, WT1 and KIT mutations in hematological malignancies with NUP98-fusion genes," Leukemia, vol. 24, no. 11, pp. 1975-1977, 2010.

[115] A. Fasan, C. Haferlach, T. Alpermann, W. Kern, T. Haferlach, and S. Schnittger, "A rare but specific subset of adult AML patients can be defined by the cytogenetically cryptic NUP98NSD1 fusion gene," Leukemia, vol. 27, no. 1, pp. 245-248, 2013.

[116] S. Akiki, S. A. Dyer, D. Grimwade et al., "NUP98-NSD1 fusion in association with FLT3-ITD mutation identifies a prognostically relevant subgroup of pediatric acute myeloid leukemia patients suitable for monitoring by real time quantitative PCR," Genes Chromosomes Cancer, vol. 52, pp. 1053-1064, 2013.

[117] S. Kaltenbach, G. Soler, C. Barin et al., "NUP98-MLL fusion in human acute myeloblastic leukemia," Blood, vol. 116, no. 13, pp. 2332-2335, 2010.

[118] J. Saw, D. J. Curtis, D. J. Hussey, A. Dobrovic, P. D. Aplan, and C. I. Slape, "The fusion partner specifies the oncogenic potential of NUP98 fusion proteins," Leukemia Research, vol. 37, pp. 1668-1673, 2013.

[119] E. R. Yassin, N. J. Sarma, A. M. Abdul-Nabi et al., "Dissection of the transformation of primary human hematopoietic cells by the oncogene NUP98-HOXA9," PLOS ONE, vol. 4, no. 8, Article ID e6719, 2009.

[120] T. Funasaka, H. Nakano, Y. Wu et al., "RNA export factor RAE1 contributes to NUP98-HOXA9-mediated leukemogenesis," Cell Cycle, vol. 10, no. 9, pp. 1456-1467, 2010.

[121] V. Salsi, S. Ferrari, P. Gorello et al., "NUP98 fusion oncoproteins promote aneuploidy by attenuating the mitotic spindle checkpoint," Cancer Research, vol. 74, pp. 1079-1090, 2014.

[122] A. M. Forrester, C. Grabher, E. R. Mcbride et al., "NUP98HOXA9-transgenic zebrafish develop a myeloproliferative neoplasm and provide new insight into mechanisms of myeloid leukaemogenesis," British Journal of Haematology, vol. 155, no. 2, pp. 167-181, 2011.
[123] J. van Deursen, J. Boer, L. Kasper, and G. Grosveld, “G2 arrest and impaired nucleocytoplasmic transport in mouse embryos lacking the proto-oncogene CAN/Nup214," The EMBO Journal, vol. 15, pp. 5574-5583, 1996.

[124] R. Bernad, D. Engelsma, H. Sanderson, H. Pickersgill, and M. Fornerod, "Nup214-Nup88 nucleoporin subcomplex is required for CRM1-mediated $60 \mathrm{~S}$ preribosomal nuclear export," Journal of Biological Chemistry, vol. 281, no. 28, pp. 19378-19386, 2006.

[125] S. Hutten and R. H. Kehlenbach, "Nup214 is required for CRM1-dependent nuclear protein export in vivo," Molecular and Cellular Biology, vol. 26, no. 18, pp. 6772-6785, 2006.

[126] J. Boer, J. Bonten-Surtel, and G. Grosveld, "Overexpression of the nucleoporin CAN/NUP214 induces growth arrest, nucleocytoplasmic transport defects, and apoptosis," Molecular and Cellular Biology, vol. 18, no. 3, pp. 1236-1247, 1998.

[127] D. Kraemer, R. W. Wozniak, G. Blobel, and A. Radu, "The human CAN protein, a putative oncogene product associated with myeloid leukemogenesis, is a nuclear pore complex protein that faces the cytoplasm," Proceedings of the National Academy of Sciences of the United States of America, vol. 91, no. 4, pp. 1519-1523, 1994.

[128] N. Panté, R. Bastos, I. McMorrow, B. Burke, and U. Aebi, "Interactions and three-dimensional localization of a group of nuclear pore complex proteins," Journal of Cell Biology, vol. 126, no. 3, pp. 603-617, 1994.

[129] T. C. Walther, M. Fornerod, H. Pickersgill, M. Goldberg, T. D. Allen, and I. W. Mattaj, “The nucleoporin Nup153 is required for nuclear pore basket formation, nuclear pore complex anchoring and import of a subset of nuclear proteins," The EMBO Journal, vol. 20, no. 20, pp. 5703-5714, 2001.

[130] M. Fornerod, J. van Deursen, S. van Baal et al., "The human homologue of yeast CRM1 is in a dynamic subcomplex with CAN/Nup214 and a novel nuclear pore component Nup88," The EMBO Journal, vol. 16, pp. 807-816, 1997.

[131] R. Bastos, L. R. de Pouplana, M. Enarson, K. Bodoor, and B. Burke, "Nup84, a novel nucleoporin that is associated with CAN/Nup214 on the cytoplasmic face of the nuclear pore complex," The Journal of Cell Biology, vol. 137, pp. 989-1000, 1997.

[132] N. Xylourgidis, P. Roth, N. Sabri, V. Tsarouhas, and C. Samakovlis, "The nucleoporin Nup214 sequesters CRM1 at the nuclear rim and modulates NFאB activation in Drosophila," Journal of Cell Science, vol. 119, no. 21, pp. 4409-4419, 2006.

[133] P. Roth, N. Xylourgidis, N. Sabri, A. Uv, M. Fornerod, and C. Samakovlis, "The Drosophila nucleoporin DNup88 localizes DNup214 and CRM1 on the nuclear envelope and attenuates NES-mediated nuclear export," Journal of Cell Biology, vol. 163, no. 4, pp. 701-706, 2003.

[134] R. Bernad, H. van der Velde, M. Fornerod, and H. Pickersgill, "Nup358/RanBP2 attaches to the nuclear pore complex via association with Nup88 and Nup214/CAN and plays a supporting role in CRM1-mediated nuclear protein export," Molecular and Cellular Biology, vol. 24, no. 6, pp. 2373-2384, 2004.

[135] U. Stochaj, P. Bański, M. Kodiha, and N. Matusiewicz, "The Nterminal domain of the mammalian nucleoporin p62 interacts with other nucleoporins of the FXFG family during interphase," Experimental Cell Research, vol. 312, no. 13, pp. 2490-2499, 2006.

[136] J. Napetschnig, G. Blobel, and A. Hoelz, "Crystal structure of the N-terminal domain of the human protooncogene Nup214/CAN," Proceedings of the National Academy of Sciences of the United States of America, vol. 104, no. 6, pp. 1783-1788, 2007. 
[137] B. Montpetit, N. D. Thomsen, K. J. Helmke, M. A. Seeliger, J. M. Berger, and K. Weis, "A conserved mechanism of DEADbox ATPase activation by nucleoporins and InsP6 in mRNA export," Nature, vol. 472, no. 7342, pp. 238-244, 2011.

[138] H. von Moeller, C. Basquin, and E. Conti, "The mRNA export protein DBP5 binds RNA and the cytoplasmic nucleoporin NUP214 in a mutually exclusive manner," Nature Structural and Molecular Biology, vol. 16, no. 3, pp. 247-254, 2009.

[139] C. S. Weirich, J. P. Erzberger, J. M. Berger, and K. Weis, “The Nterminal domain of Nup159 forms a $\beta$-propeller that functions in mRNA export by tethering the helicase Dbp5 to the nuclear pore," Molecular Cell, vol. 16, no. 5, pp. 749-760, 2004.

[140] J. Napetschnig, S. A. Kassube, E. W. Debler, R. W. Wong, G. Blobel, and A. Hoelz, "Structural and functional analysis of the interaction between the nucleoporin Nup214 and the DEADbox helicase Ddx19," Proceedings of the National Academy of Sciences of the United States of America, vol. 106, no. 9, pp. 3089-3094, 2009.

[141] S. Kuersten, G. J. Arts, T. C. Walther, L. Englmeier, and I. W. Mattaj, "Steady-state nuclear localization of exportin-t involves RanGTP binding and two distinct nuclear pore complex interaction domains," Molecular and Cellular Biology, vol. 22, no. 16, pp. 5708-5720, 2002.

[142] J. Katahira, K. Sträßer, A. Podtelejnikov, M. Mann, J. U. Jung, and E. Hurt, "The Mex67p-mediated nuclear mRNA export pathway is conserved from yeast to human," The EMBO Journal, vol. 18, no. 9, pp. 2593-2609, 1999.

[143] S. Roloff, C. Spillner, and R. H. Kehlenbach, "Several phenylalanine-glycine motives in the nucleoporin Nup214 are essential for binding of the nuclear export receptor CRM1," Journal of Biological Chemistry, vol. 288, no. 6, pp. 3952-3963, 2013.

[144] C. Rollenhagen, P. Mühlhäusser, U. Kutay, and N. Panté, "Importin $\beta$-depending nuclear import pathways: role of the adapter proteins in the docking and releasing steps," Molecular Biology of the Cell, vol. 14, no. 5, pp. 2104-2115, 2003.

[145] L. Xu, Y. Kang, S. Çöl, and J. Massagué, "Smad2 nucleocytoplasmic shuttling by nucleoporins CAN/Nup214 and Nup153 feeds TGF $\beta$ signaling complexes in the cytoplasm and nucleus," Molecular Cell, vol. 10, no. 2, pp. 271-282, 2002.

[146] J. A. Carman and S. G. Nadler, "Direct association of tristetraprolin with the nucleoporin CAN/Nup214," Biochemical and Biophysical Research Communications, vol. 315, no. 2, pp. 445-449, 2004.

[147] C. G. Besirli, E. F. Wagner, and E. M. Johnson Jr., "The limited role of $\mathrm{NH} 2$-terminal c-Jun phosphorylation in neuronal apoptosis: identification of the nuclear pore complex as a potential target of the JNK pathway," Journal of Cell Biology, vol. 170, no. 3, pp. 401-411, 2005.

[148] S. Strunze, M. F. Engelke, I.-H. Wang et al., "Kinesin-1-mediated capsid disassembly and disruption of the nuclear pore complex promote virus infection," Cell Host and Microbe, vol. 10, no. 3, pp. 210-223, 2011.

[149] S. Strunze, L. C. Trotman, K. Boucke, and U. F. Greber, "Nuclear targeting of adenovirus type 2 requires CRM1mediated nuclear export," Molecular Biology of the Cell, vol. 16, no. 6, pp. 2999-3009, 2005.

[150] M. von Lindern, D. Breems, S. van Baal, H. Adriaansen, and G. Grosveld, "Characterization of the translocation breakpoint sequences of two DEK-CAN fusion genes present in $t(6 ; 9)$ acute myeloid leukemia and a SET-CAN fusion gene found in a case of acute undifferentiated leukemia," Genes Chromosomes and Cancer, vol. 5, no. 3, pp. 227-234, 1992.
[151] C. Graux, J. Cools, C. Melotte et al., "Fusion of NUP214 to ABL1 on amplified episomes in T-cell acute lymphoblastic leukemia," Nature Genetics, vol. 36, no. 10, pp. 1084-1089, 2004.

[152] P. Gorello, R. la Starza, D. di Giacomo et al., "SQSTM1-NUP214: a new gene fusion in adult T-cell acute lymphoblastic leukemia," Haematologica, vol. 95, no. 12, pp. 2161-2163, 2010.

[153] S. Saito, M. Miyaji-Yamaguchi, and K. Nagata, "Aberrant intracellular localization of set-can fusion protein, associated with a leukemia, disorganizes nuclear export," International Journal of Cancer, vol. 111, no. 4, pp. 501-507, 2004.

[154] K. de Keersmaecker, J. L. Rocnik, R. Bernad et al., "Kinase activation and transformation by NUP214-ABL1 is dependent on the context of the nuclear pore," Molecular Cell, vol. 31, no. 1, pp. 134-142, 2008.

[155] K. de Keersmaecker, M. Versele, J. Cools, G. Superti-Furga, and O. Hantschel, "Intrinsic differences between the catalytic properties of the oncogenic NUP214-ABL1 and BCR-ABL1 fusion protein kinases," Leukemia, vol. 22, no. 12, pp. 2208-2216, 2008.

[156] M. Fornerod, J. Boer, S. van Baal et al., "Relocation of the carboxyterminal part of CAN from the nuclear envelope to the nucleus as a result of leukemia-specific chromosome rearrangements," Oncogene, vol. 10, no. 9, pp. 1739-1748, 1995.

[157] P. van Vlierberghe, M. van Grotel, J. Tchinda et al., "The recurrent SET-NUP214 fusion as a new HOXA activation mechanism in pediatric T-cell acute lymphoblastic leukemia," Blood, vol. 111, no. 9, pp. 4668-4680, 2008.

[158] U. Özbek, A. Kandilci, S. van Baal et al., "SET-CAN, the product of the $t(9 ; 9)$ in acute undifferentiated leukemia, causes expansion of early hematopoietic progenitors and hyperproliferation of stomach mucosa in transgenic mice," The American Journal of Pathology, vol. 171, no. 2, pp. 654-666, 2007.

[159] M. von Lindern, M. Fornerod, S. van Baal et al., "The translocation $(6 ; 9)$, associated with a specific subtype of acute myeloid leukemia, results in the fusion of two genes, dek and can, and the expression of a chimeric, leukemia-specific dek-can mRNA," Molecular and Cellular Biology, vol. 12, no. 4, pp. 1687-1697, 1992.

[160] R. ben Abdelali, A. Roggy, T. Leguay et al., "SET-NUP214 is a recurrent gammadelta lineage specific fusion transcript associated with cortico/chemoresistance in adult T-ALL," Blood, vol. 123, no. 12, pp. 1860-1863, 2014.

[161] J. D. Sandahl, E. A. Coenen, E. Forestier et al., " $t(6 ; 9)(p 22 ; q 34) /$ DEK-NUP214 rearranged pediatric myeloid leukemia: an international study on 62 patients," Haematologica, vol. 99, no. 5, pp. 865-872, 2014.

[162] M. Ageberg, K. Drott, T. Olofsson, U. Gullberg, and A. Lindmark, "Identification of a novel and myeloid specific role of the leukemia-associated fusion protein DEK-NUP214 leading to increased protein synthesis," Genes Chromosomes and Cancer, vol. 47, no. 4, pp. 276-287, 2008.

[163] C. Sanden, M. Ageberg, J. Petersson, A. Lennartsson, and U. Gullberg, "Forced expression of the DEK-NUP214 fusion protein promotes proliferation dependent on upregulation of mTOR," BMC Cancer, vol. 13, article 440, 2013.

[164] C. Graux, M. Stevens-Kroef, M. Lafage et al., "Heterogeneous patterns of amplification of the NUP214-ABL1 fusion gene in T-cell acute lymphoblastic leukemia," Leukemia, vol. 23, no. 1, pp. 125-133, 2009.

[165] P. Ballerini, M. Busson, S. Fasola et al., "NUP214-ABL1 amplification in $\mathrm{t}(5 ; 14)$ /HOX11L2-positive ALL present with several forms and may have a prognostic significance," Leukemia, vol. 19, no. 3, pp. 468-470, 2005. 
[166] K. de Keersmaecker, M. Porcu, L. Cox et al., "NUP214-ABL1mediated cell proliferation in T-cell acute lymphoblastic leukemia is dependent on the LCK kinase and various interacting proteins," Haematologica, vol. 99, pp. 85-93, 2014.

[167] H. Quentmeier, B. Schneider, S. Röhrs et al., "SET-NUP214 fusion in acute myeloid leukemia-and T-cell acute lymphoblastic leukemia-derived cell lines," Journal of Hematology and Oncology, vol. 2, article 3, 2009.

[168] J. Wu, M. J. Matunis, D. Kraemer, G. Blobel, and E. Coutavas, "Nup358, a cytoplasmically exposed nucleoporin with peptide repeats, Ran- GTP binding sites, zinc fingers, a cyclophilin A homologous domain, and a leucine-rich region," Journal of Biological Chemistry, vol. 270, no. 23, pp. 14209-14213, 1995.

[169] T. C. Walther, H. S. Pickersgill, V. C. Cordes et al., "The cytoplasmic filaments of the nuclear pore complex are dispensable for selective nuclear protein import," Journal of Cell Biology, vol. 158, no. 1, pp. 63-77, 2002.

[170] N. Yokoyama, H. Hayashi, T. Seki et al., "A giant nucleopore protein that binds Ran/TC4," Nature, vol. 376, no. 6536, pp. 184-188, 1995.

[171] S. Hutten, A. Flotho, F. Melchior, and R. H. Kehlenbach, “The Nup358-RanGAP complex is required for efficient importin $\alpha / \beta$-dependent nuclear import," Molecular Biology of the Cell, vol. 19, no. 5, pp. 2300-2310, 2008.

[172] S. Hutten, S. Wälde, C. Spillner, J. Hauber, and R. H. Kehlenbach, "The nuclear pore component Nup358 promotes transportin-dependent nuclear import," Journal of Cell Science, vol. 122, no. 8, pp. 1100-1110, 2009.

[173] S. Wälde, K. Thakar, S. Hutten et al., "The nucleoporin Nup358/RanBP2 promotes nuclear import in a cargo- and transport receptor-specific manner," Traffic, vol. 13, no. 2, pp. 218-233, 2012.

[174] B. B. Singh, H. H. Patel, R. Roepman, D. Schick, and P. A. Ferreira, "The zinc finger cluster domain of RanBP2 is a specific docking site for the nuclear export factor, exportin-1," Journal of Biological Chemistry, vol. 274, no. 52, pp. 37370-37378, 1999.

[175] M. Hamada, A. Haeger, K. B. Jeganathan et al., "Ran-dependent docking of importin $\beta$ - to RanBP2/Nup358 filaments is essential for protein import and cell viability," Journal of Cell Biology, vol. 194, no. 4, pp. 597-612, 2011.

[176] D. Salina, P. Enarson, J. B. Rattner, and B. Burke, "Nup358 integrates nuclear envelope breakdown with kinetochore assembly," Journal of Cell Biology, vol. 162, no. 6, pp. 991-1001, 2003.

[177] A. Arnaoutov, Y. Azuma, K. Ribbeck et al., "Crm1 is a mitotic effector of Ran-GTP in somatic cells," Nature Cell Biology, vol. 7, no. 6, pp. 626-632, 2005.

[178] J. Joseph, S.-T. Liu, S. A. Jablonski, T. J. Yen, and M. Dasso, "The RanGAP1-RanBP2 complex is essential for microtubulekinetochore interactions in vivo," Current Biology, vol. 14, no. 7, pp. 611-617, 2004.

[179] C. Hashizume, A. Kobayashi, and R. W. Wong, "Downmodulation of nucleoporin RanBP2/Nup358 impaired chromosomal alignment and induced mitotic catastrophe," Cell Death and Disease, vol. 4, article e854, 2013.

[180] A. Pichler, A. Gast, J. S. Seeler, A. Dejean, and F. Melchior, "The nucleoporin RanBP2 has SUMO1 E3 ligase activity," Cell, vol. 108, no. 1, pp. 109-120, 2002.

[181] U. R. Klein, M. Haindl, E. A. Nigg, and S. Muller, "RanBP2 and SENP3 function in a mitotic SUMO2/3 conjugationdeconjugation cycle on borealin," Molecular Biology of the Cell, vol. 20, no. 1, pp. 410-418, 2009.
[182] O. Kirsh, J.-S. Seeler, A. Pichler et al., "The SUMO E3 ligase RanBP2 promotes modification of the HDAC4 deacetylase," The EMBO Journal, vol. 21, no. 11, pp. 2682-2691, 2002.

[183] M. M. Dawlaty, L. Malureanu, K. B. Jeganathan et al., "Resolution of sister centromeres requires RanBP2-mediated SUMOylation of topoisomerase IIalpha," Cell, vol. 133, no. 1, pp. 103-115, 2008.

[184] A. Werner, A. Flotho, and F. Melchior, "The RanBP2/ RanGAP1*SUMO1/Ubc9 complex is a multisubunit SUMO E3 ligase," Molecular Cell, vol. 46, no. 3, pp. 287-298, 2012.

[185] K. Mahadevan, H. Zhang, A. Akef et al., "RanBP2/Nup358 potentiates the translation of a subset of mRNAs encoding secretory proteins," PLoS Biology, vol. 11, no. 4, Article ID e1001545, 2013.

[186] K.-I. Cho, H. Yi, N. Tserentsoodol, K. Searle, and P. A. Ferreira, "Neuroprotection resulting from insufficiency of RANBP2 is associated with the modulation of protein and lipid homeostasis of functionally diverse but linked pathways in response to oxidative stress," DMM Disease Models and Mechanisms, vol. 3, no. 9-10, pp. 595-604, 2010.

[187] K.-I. Cho, H. Yi, A. Yeh et al., "Haploinsufficiency of RanBP2 is neuroprotective against light-elicited and age-dependent degeneration of photoreceptor neurons," Cell Death and Differentiation, vol. 16, no. 2, pp. 287-297, 2009.

[188] Y. Cai, B. B. Singh, A. Aslanukov, H. Zhao, and P. A. Ferreira, "The docking of kinesins, KIF5B and KIF5C, to ran-binding protein 2 (RanBP2) is mediated via a novel RanBP2 domain," Journal of Biological Chemistry, vol. 276, no. 45, pp. 4159441602, 2001.

[189] T. A. Mavlyutov, Y. Cai, and P. A. Ferreira, "Identification of RanBP2- and kinesin-mediated transport pathways with restricted neuronal and subcellular localization," Traffic, vol. 3, no. 9, pp. 630-640, 2002.

[190] D. Splinter, M. E. Tanenbaum, A. Lindqvist et al., "Bicaudal D2, dynein, and kinesin-1 associate with nuclear pore complexes and regulate centrosome and nuclear positioning during mitotic entry," PLoS Biology, vol. 8, no. 4, 2010.

[191] M. Asally, Y. Yasuda, M. Oka et al., "Nup358, a nucleoporin, functions as a key determinant of the nuclear pore complex structure remodeling during skeletal myogenesis," The FEBS Journal, vol. 278, no. 4, pp. 610-621, 2011.

[192] K. I. Cho, M. Haque, J. Wang et al., "Distinct and atypical intrinsic and extrinsic cell death pathways between photoreceptor cell types upon specific ablation of Ranbp2 in cone photoreceptors," PLoS Genetics, vol. 9, Article ID e1003555, 2013.

[193] C. Frohnert, S. Hutten, S. Walde, A. Nath, and R. H. Kehlenbach, "Importin 7 and nup358 promote nuclear import of the protein component of human telomerase," PLoS ONE, vol. 9, Article ID e88887, 2014

[194] J. Joseph and M. Dasso, "The nucleoporin Nup358 associates with and regulates interphase microtubules," The FEBS Letters, vol. 582, no. 2, pp. 190-196, 2008.

[195] P. Murawala, M. M. Tripathi, P. Vyas, A. Salunke, and J. Joseph, "Nup358 interacts with APC and plays a role in cell polarization," Journal of Cell Science, vol. 122, no. 17, pp. 3113-3122, 2009.

[196] M. Gloerich, M. J. Vliem, E. Prummel et al., “The nucleoporin RanBP2 tethers the cAMP effector Epacl and inhibits its catalytic activity," Journal of Cell Biology, vol. 193, no. 6, pp. 1009-1020, 2011.

[197] M. Gloerich and J. L. Bos, "Epac: defining a new mechanism for cAMP action," Annual Review of Pharmacology and Toxicology, vol. 50, pp. 355-375, 2010. 
[198] P. A. Ferreira, T. A. Nakayama, W. L. Pak, and G. H. Travis, "Cyclophilin-related protein RanBP2 acts as chaperone for red/green opsin," Nature, vol. 383, pp. 637-640, 1996.

[199] P. A. Ferreira, T. A. Nakayama, and G. H. Travis, "Interconversion of red opsin isoforms by the cyclophilin-related chaperone protein Ran-binding protein 2," Proceedings of the National Academy of Sciences of the United States of America, vol. 94, pp. 1556-1561, 1997.

[200] A. Aslanukov, R. Bhowmick, M. Guruju et al., "RanBP2 modulates Coxll and hexokinase I activities and haploinsufficiency of RanBP2 causes deficits in glucose metabolism," PLoS Genetics, vol. 2, no. 10, p. e177, 2006.

[201] K.-I. Cho, Y. Cai, H. Yi, A. Yeh, A. Aslanukov, and P. A. Ferreira, "Association of the kinesin-binding domain of RanBP2 to KIF5B and KIF5C determines mitochondria localization and function," Traffic, vol. 8, no. 12, pp. 1722-1735, 2007.

[202] K.-I. Cho, H. Yi, R. Desai, A. R. Hand, A. L. Haas, and P. A. Ferreira, "RANBP2 is an allosteric activator of the conventional kinesin-1 motor protein, KIF5B, in a minimal cell-free system," EMBO Reports, vol. 10, no. 5, pp. 480-486, 2009.

[203] C. Gervais, L. Dano, N. Perrusson et al., "A translocation $\mathrm{t}(2 ; 8)$ (q12;p11) fuses FGFR1 to a novel partner gene, RANBP2/NUP358, in a myeloproliferative/myelodysplastic neoplasm," Leukemia, vol. 27, no. 5, pp. 1186-1188, 2013.

[204] J. H. Lim, S. Jang, C. J. Park et al., "RANBP2-ALK fusion combined with monosomy 7 in acute myelomonocytic leukemia," Cancer Genetics, vol. 207, no. 1-2, pp. 40-45, 2014.

[205] S. E. Lee, S. Y. Kang, K. Takeuchi, and Y. H. Ko, "Identification of RANBP2-ALK fusion in ALK positive diffuse large B-cell lymphoma," Hematological Oncology, 2014.

[206] Z. Ma, D. A. Hill, M. H. Collins et al., "Fusion of ALK to the Ran-binding protein 2 (RANBP2) gene in inflammatory myofibroblastic tumor," Genes Chromosomes and Cancer, vol. 37, no. 1, pp. 98-105, 2003.

[207] A. Mariño-Enríquez, W.-L. Wang, A. Roy et al., "Epithelioid inflammatory myofibroblastic sarcoma: an aggressive intraabdominal variant of inflammatory myofibroblastic tumor with nuclear membrane or perinuclear alk," The American Journal of Surgical Pathology, vol. 35, no. 1, pp. 135-144, 2011.

[208] S.-T. Chen and J.-C. Lee, "An inflammatory myofibroblastic tumor in liver with ALK and RANBP2 gene rearrangement: combination of distinct morphologic, immunohistochemical, and genetic features," Human Pathology, vol. 39, no. 12, pp. 1854-1858, 2008.

[209] J. Li, W. H. Yin, K. Takeuchi, H. Guan, Y. H. Huang, and J. K. Chan, "Inflammatory myofibroblastic tumor with RANBP2 and ALK gene rearrangement: a report of two cases and literature review," Diagnostic Pathology, vol. 8, article 147, 2013.

[210] A. S. Patel, K. M. Murphy, A. L. Hawkins et al., "RANBP2 and CLTC are involved in ALK rearrangements in inflammatory myofibroblastic tumors," Cancer Genetics and Cytogenetics, vol. 176, no. 2, pp. 107-114, 2007.

[211] Y. Maesako, K. Izumi, S. Okamori et al., "inv(2)(p23q13)/RANbinding protein 2 (RANBP2)-ALK fusion gene in myeloid leukemia that developed in an elderly woman," International Journal of Hematology, vol. 99, pp. 202-207, 2014.

[212] S. Hutten and R. H. Kehlenbach, "CRM1-mediated nuclear export: to the pore and beyond," Trends in Cell Biology, vol. 17, no. 4, pp. 193-201, 2007.

[213] P. Ranganathan, X. Yu, C. Na et al., "Preclinical activity of a novel CRM1 inhibitor in acute myeloid leukemia," Blood, vol. 120, no. 9, pp. 1765-1773, 2012.
[214] G. Ghannam, A. Takeda, T. Camarata, M. A. Moore, A. Viale, and N. R. Yaseen, "The oncogene Nup98-HOXA9 induces gene transcription in myeloid cells," Journal of Biological Chemistry, vol. 279, no. 2, pp. 866-875, 2004.

[215] T. Fujino, A. Suzuki, Y. Ito et al., "Single-translocation and double-chimeric transcripts: detection of NUP98-HOXA9 in myeloid leukemias with hOXA11 or HOXA13 breaks of the chromosomal translocation $\mathrm{t}(7 ; 11)(\mathrm{p} 15 ; \mathrm{p} 15)$, , Blood, vol. 99, no. 4, pp. 1428-1433, 2002.

[216] Y. Mizoguchi, N. Fujita, T. Taki, Y. Hayashi, and K. Hamamoto, "Juvenile myelomonocytic leukemia with $\mathrm{t}(7 ; 11)(\mathrm{p} 15 ; \mathrm{p} 15)$ and NUP98-HOXA11 fusion," The American Journal of Hematology, vol. 84, no. 5, pp. 295-297, 2009.

[217] A. Suzuki, Y. Ito, G. Sashida et al., "t(7;11)(p15;p15) chronic myeloid leukaemia developed into blastic transformation showing a novel NUP98/HOXA11 fusion," British Journal of Haematology, vol. 116, no. 1, pp. 170-172, 2002.

[218] J. Nakahara, K. Kanekura, M. Nawa, S. Aiso, and N. Suzuki, "Abnormal expression of TIP30 and arrested nucleocytoplasmic transport within oligodendrocyte precursor cells in multiple sclerosis," Journal of Clinical Investigation, vol. 119, no. 1, pp. 169-181, 2009.

[219] T. Taketani, T. Taki, R. Ono, Y. Kobayashi, K. Ida, and Y. Hayashi, "The chromosome translocation $\mathrm{t}(7 ; 11)(\mathrm{p} 15 ; 15)$ in acute myeloid leukemia results in fusion of the NUP98 gene with a HOXA cluster gene, HOXA13, but not HOXA9," Genes Chromosomes and Cancer, vol. 34, no. 4, pp. 437-443, 2002.

[220] B.-W. Gu, Q. Wang, J.-M. Wang et al., "Major form of NUP98/HOXC11 fusion in adult AMLwith $\mathrm{t}(11 ; 12)(\mathrm{p} 15 ; \mathrm{q} 13)$ translocation exhibits aberrant trans-regulatory activity," Leukemia, vol. 17, no. 9, pp. 1858-1864, 2003.

[221] T. Taketani, T. Taki, N. Shibuya, A. Kikuchi, R. Hanada, and Y. Hayashi, "Novel NUP98-HOXC11 fusion gene resulted from a chromosomal break within exon 1 of HOXC11 in acute myeloid leukemia with $\mathrm{t}(11 ; 12)(\mathrm{p} 15 ; \mathrm{q} 13)$," Cancer Research, vol. 62, no. 16, pp. 4571-4574, 2002.

[222] R. La Starza, M. Trubia, B. Crescenzi et al., "Human homeobox gene HOXCI3 is the partner of NUP98 in adult acute myeloid leukemia with $\mathrm{t}(11 ; 12)(\mathrm{p} 15 ; \mathrm{q} 13), "$ Genes Chromosomes and Cancer, vol. 36, no. 4, pp. 420-423, 2003.

[223] I. Panagopoulos, M. Isaksson, R. Billström, B. Strömbeck, F. Mitelman, and B. Johansson, "Fusion of the NUP98 gene and the homeobox gene HOXC13 in acute myeloid leukemia with t(11;12)(p15;q13)," Genes Chromosomes and Cancer, vol. 36, no. 1, pp. 107-112, 2003.

[224] N. Tošić, M. Stojiljković, N. Colović, M. Čolović, and S. Pavlović, "Acute myeloid leukemia with NUP98-HOXC13 fusion and FLT3 internal tandem duplication mutation: case report and literature review," Cancer Genetics and Cytogenetics, vol. 193, no. 2, pp. 98-103, 2009.

[225] K. Terui, J. Kitazawa, Y. Takahashi et al., "Successful treatment of acute myelomonocytic leukaemia with NUP98-HOXD11 fusion transcripts and monitoring of minimal residual disease," British Journal of Haematology, vol. 120, no. 2, pp. 274-276, 2003.

[226] Y. Arai, T. Kyo, H. Miwa et al., "Heterogeneous fusion transcripts involving the NUP98 gene and HOXD13 gene activation in a case of acute myeloid leukemia with the $\mathrm{t}(2 ; 11)(\mathrm{q} 31 ; \mathrm{p} 15)$ translocation," Leukemia, vol. 14, no. 9, pp. 1621-1629, 2000.

[227] M. Emerenciano, C. Meyer, M. L. MacEdo-Silva et al., "Backtracking to birth of the NUP98-HOXD13 gene fusion in an infant acute myeloid leukemia," Leukemia, vol. 25, no. 7, pp. 1192-1194, 2011. 
[228] S. Z. Raza-Egilmez, S. N. Jani-Sait, M. Grossi, M. J. Higgins, T. B. Shows, and P. D. Aplan, "NUP98-HOXD13 gene fusion in therapy-related acute myelogenous leukemia," Cancer Research, vol. 58, no. 19, pp. 4269-4273, 1998.

[229] H. Shimada, Y. Arai, S. Sekiguchi, T. Ishii, S. Tanitsu, and M. Sasaki, "Generation of the NUP98-HOXD13 fusion transcript by a rare translocation, $\mathrm{t}(2 ; 11)(\mathrm{q} 31 ; \mathrm{p} 15)$, in a case of infant leukaemia," British Journal of Haematology, vol. 110, no. 1, pp. 210-213, 2000.

[230] Y. N. Kobzev, J. Martinez-Climent, S. Lee, J. Chen, and J. D. Rowley, "Analysis of translocations that involve the NUP98 gene in patients with $11 \mathrm{p} 15$ chromosomal rearrangements," Genes Chromosomes and Cancer, vol. 41, no. 4, pp. 339-352, 2004.

[231] T. Nakamura, Y. Yamazaki, Y. Hatano, and I. Miura, "NUP98 is fused to PMX1 homeobox gene in human acute myelogenous leukemia with chromosome translocation t(1;11)(q23;p15)," Blood, vol. 94, no. 2, pp. 741-747, 1999.

[232] L. Zhang, R. Alsabeh, C. Mecucci et al., "Rare t(1;11)(q23;p15) in therapy-related myelodysplastic syndrome evolving into acute myelomonocytic leukemia: a case report and review of the literature," Cancer Genetics and Cytogenetics, vol. 178, no. 1, pp. 42-48, 2007.

[233] C. Gervais, L. Mauvieux, N. Perrusson et al., "A new translocation $\mathrm{t}(9 ; 11)(\mathrm{q} 34 ; \mathrm{p} 15)$ fuses NUP98 to a novel homeobox partner gene, PRRX2, in a therapy-related acute myeloid leukemia," Leukemia, vol. 19, no. 1, pp. 145-148, 2005.

[234] S. Lisboa, N. Cerveira, S. Bizarro et al., "POU1F1 is a novel fusion partner of NUP98 in acute myeloid leukemia with t(3;11)(p11;p15)," Molecular Cancer, vol. 12, no. 1, article 5, 2013.

[235] G. Soler, S. Kaltenbach, S. Dobbelstein et al., "Identification of GSX2 and AF10 as NUP98 partner genes in myeloid malignancies," Blood Cancer Journal, vol. 3, article e124, 2013.

[236] J. C. Reader, J. S. Meekins, I. Gojo, and Y. Ning, "A novel NUP98-PHF23 fusion resulting from a cryptic translocation $\mathrm{t}(11 ; 17)(\mathrm{p} 15 ; \mathrm{p} 13)$ in acute myeloid leukemia," Leukemia, vol. 21, no. 4, pp. 842-844, 2007.

[237] J. D. E. de Rooij, I. H. I. M. Hollink, S. T. C. J. M. ArentsenPeters et al., "NUP98/JARID1A is a novel recurrent abnormality in pediatric acute megakaryoblastic leukemia with a distinct HOX gene expression pattern," Leukemia, 2013.

[238] L. J. C. M. van Zutven, E. Önen, S. C. J. M. Velthuizen et al., "Identification of NUP98 abnormalities in acute leukemia: JARIDIA (12p13) as a new partner gene," Genes Chromosomes and Cancer, vol. 45, no. 5, pp. 437-446, 2006.

[239] I. H. I. M. Hollink, M. M. van den Heuvel-Eibrink, S. T. C. J. M. Arentsen-Peters et al., "NUP98/NSD1 characterizes a novel poor prognostic group in acute myeloid leukemia with a distinct HOX gene expression pattern," Blood, vol. 118, no. 13, pp. 3645-3656, 2011.

[240] R. J. Jaju, C. Fidler, O. A. Haas et al., "A novel gene, NSD1, is fused to NUP98 in the $\mathrm{t}(5 ; 11)(\mathrm{q} 35 ; \mathrm{p} 15.5)$ in de novo childhood acute myeloid leukemia," Blood, vol. 98, no. 4, pp. 1264-1267, 2001.

[241] R. La Starza, P. Gorello, R. Rosati et al., "Cryptic insertion producing two NUP98/NSD1 chimeric transcripts in adult refractory anemia with an excess of blasts," Genes Chromosomes and Cancer, vol. 41, no. 4, pp. 395-399, 2004.

[242] C. Panarello, C. Rosanda, and C. Morerio, "Cryptic translocation $\mathrm{t}(5 ; 11)(\mathrm{q} 35 ; \mathrm{p} 15.5)$ with involvement of the NSD1 and NUP98 genes without $5 \mathrm{q}$ deletion in childhood acute myeloid leukemia," Genes Chromosomes and Cancer, vol. 35, no. 3, pp. 277-281, 2002.
[243] A. Petit, I. Radford, M.-C. Waill, S. Romana, and R. Berger, "NUP98-NSD1 fusion by insertion in acute myeloblastic leukemia," Cancer Genetics and Cytogenetics, vol. 180, no. 1, pp. 43-46, 2008.

[244] F. Thol, B. Kölking, I. H. I. Hollink et al., "Analysis of NUP98/NSD1 translocations in adult AML and MDS patients," Leukemia, vol. 27, no. 3, pp. 750-754, 2013.

[245] R. Rosati, R. La Starza, A. Veronese et al., "NUP98 is fused to the NSD3 gene in acute myeloid leukemia associated with t(8;11)(p11.2;p15)," Blood, vol. 99, no. 10, pp. 3857-3860, 2002.

[246] T. Taketani, T. Taki, H. Nakamura, M. Taniwaki, J. Masuda, and Y. Hayashi, "NUP98-NSD3 fusion gene in radiation-associated myelodysplastic syndrome with $\mathrm{t}(8 ; 11)(\mathrm{p} 11 ; \mathrm{p} 15)$ and expression pattern of NSD family genes," Cancer Genetics and Cytogenetics, vol. 190, no. 2, pp. 108-112, 2009.

[247] I. Panagopoulos, G. Kerndrup, N. Carlsen, B. Strömbeck, M. Isaksson, and B. Johansson, "Fusion of NUP98 and the SET binding protein 1 (SETBP1) gene in a paediatric acute $\mathrm{T}$ cell lymphoblastic leukaemia with $\mathrm{t}(11 ; 18)(\mathrm{p} 15 ; \mathrm{q} 12)$," British Journal of Haematology, vol. 136, no. 2, pp. 294-296, 2007.

[248] A. Petit, C. Ragu, V. Della-Valle et al., "NUP98-HMGB3: a novel oncogenic fusion," Leukemia, vol. 24, no. 3, pp. 654-658, 2010.

[249] H. G. Ahuja, C. A. Felix, and P. D. Aplan, "Potential role for DNA topoisomerase II poisons in the generation of t(11;20)(p15;q11) translocations," Genes Chromosomes Cancer, vol. 29, pp. 96-105, 2000.

[250] H. G. Ahuja, C. A. Felix, and P. D. Aplan, “The t(11;20)(p15;q11) chromosomal translocation associated with therapy-related myelodysplastic syndrome results in an NUP98-TOP1 fusion," Blood, vol. 94, no. 9, pp. 3258-3261, 1999.

[251] S. Chen, Y. Xue, Z. Chen, Y. Guo, Y. Wu, and J. Pan, "Generation of the NUP98-TOP1 fusion transcript by the $\mathrm{t}(11 ; 20)(\mathrm{p} 15 ; \mathrm{q} 11)$ in a case of acute monocytic leukemia," Cancer Genetics and Cytogenetics, vol. 140, no. 2, pp. 153-156, 2003.

[252] S. Iwase, N. Akiyama, T. Sekikawa et al., "Both NUP98/TOP1 and TOP1/NUP98 transcripts are detected in a de novo AML with t(11;20)(p15;q11)," Genes Chromosomes and Cancer, vol. 38, no. 1, pp. 102-105, 2003.

[253] I. Panagopoulos, T. Fioretos, M. Isaksson et al., "Expression of NUP98/TOP1, but not of TOP1/NUP98, in a treatment-related myelodysplastic syndrome with $\mathrm{t}(10 ; 20 ; 11)(\mathrm{q} 24 ; \mathrm{q} 11 ; \mathrm{p} 15)$," Genes Chromosomes and Cancer, vol. 34, no. 2, pp. 249-254, 2002.

[254] K. Nebral, H. H. Schmidt, O. A. Haas, and S. Strehl, "NUP98 is fused to topoisomerase (DNA) $\mathrm{II} \beta 180 \mathrm{kDa}$ (TOP2B) in a patient with acute myeloid leukemia with a new t(3;11)(p24;p15)," Clinical Cancer Research, vol. 11, no. 18, pp. 6489-6494, 2005.

[255] K. Nakao, M. Nishino, K. Takeuchi et al., "Fusion of the nucleoporin gene, NUP98, and the putative RNA helicase gene, DDX10, by inversion 11 (p15q22) chromosome translocation in a patient with etoposide-related myelodysplastic syndrome," Internal Medicine, vol. 39, no. 5, pp. 412-415, 2000.

[256] T. Ikeda, K. Ikeda, K. Sasaki, K. Kawakami, and J. Takahara, "The inv(11)(p15q22) chromosome translocation of therapyrelated myelodysplasia with NUP98-DDX10 and DDX10NUP98 fusion transcripts," International Journal of Hematology, vol. 69, no. 3, pp. 160-164, 1999.

[257] C. Morerio, M. Acquila, A. Rapella, E. Tassano, C. Rosanda, and C. Panarello, "Inversion (11)(p15q22) with NUP98-DDX10 fusion gene in pediatric acute myeloid leukemia," Cancer Genetics and Cytogenetics, vol. 171, no. 2, pp. 122-125, 2006. 
[258] M. Yamamoto, K. Kakihana, T. Kurosu, N. Murakami, and O. Miura, "Clonal evolution with inv(11)(p15q22) and NUP98/DDX10 fusion gene in imatinib-resistant chronic myelogenous leukemia," Cancer Genetics and Cytogenetics, vol. 157, no. 2, pp. 104-108, 2005.

[259] G. Cimino, T. Sprovieri, M. C. Rapanotti, R. Foà, C. Mecucci, and F. Mandelli, "Molecular evaluation of the NUP98/RAP1GDS1 gene frequency in adults with T-acute lymphoblastic leukemia," Haematologica, vol. 86, no. 4, pp. 436-437, 2001.

[260] D. J. Hussey, M. Nicola, S. Moore, G. B. Peters, and A. Dobrovic, "The (4;11)(q21;p15) translocation fuses the NUP98 and RAP1GDS1 genes and is recurrent in T-cell acute lymphocytic leukemia," Blood, vol. 94, no. 6, pp. 2072-2079, 1999.

[261] C. Mecucci, R. La Starza, M. Negrini et al., "t(4;11)(q21;p15) translocation involving NUP98 and RAP1GDS1 genes: characterization of a new subset of $\mathrm{T}$ acute lymphoblastic leukaemia," British Journal of Haematology, vol. 109, no. 4, pp. 788-793, 2000.

[262] I. Lahortiga, J. L. Vizmanos, X. Agirre et al., "NUP98 is fused to Adducin 3 in a patient with T-cell acute lymphoblastic leukemia and myeloid markers, with a new translocation t(10;11)(q25;p15)," Cancer Research, vol. 63, no. 12, pp. 30793083, 2003.

[263] M. Ishikawa, F. Yagasaki, D. Okamura et al., "A novel gene, ANKRD28 on 3p25, is fused with NUP98 on 11p15 in a cryptic 3-way translocation of $\mathrm{t}(3 ; 5 ; 11)(\mathrm{p} 25 ; \mathrm{q} 35 ; \mathrm{p} 15)$ in an adult patient with myelodysplastic syndrome/acute myelogenous leukemia," International Journal of Hematology, vol. 86, no. 3, pp. 238-245, 2007.

[264] H. G. Ahuja, J. Hong, P. D. Aplan, L. Tcheurekdjian, S. J. Forman, and M. L. Slovak, "t(9;11)(p22;p15) in acute myeloid leukemia results in a fusion between NUP98 and the gene encoding transcriptional coactivators p52 and p75-lens epithelium-derived growth factor (LEDGF)," Cancer Research, vol. 60, no. 22, pp. 6227-6229, 2000.

[265] F. H. Grand, P. Koduru, N. C. P. Cross, and S. L. Allen, "NUP98LEDGF fusion and $\mathrm{t}(9 ; 11)$ in transformed chronic myeloid leukemia," Leukemia Research, vol. 29, no. 12, pp. 1469-1472, 2005.

[266] D. J. Hussey, S. Moore, M. Nicola, and A. Dobrovic, "Fusion of the NUP98 gene with the LEDGF/p52 gene defines a recurrent acute myeloid leukemia translocation," BMC Genetics, vol. 2, article 20, 2001.

[267] C. Morerio, M. Acquila, C. Rosanda et al., "t(9;11)(p22;p15) with NUP98-LEDGF fusion gene in pediatric acute myeloid leukemia," Leukemia Research, vol. 29, no. 4, pp. 467-470, 2005.

[268] Q. Pan, Y.-J. Zhu, B.-W. Gu et al., "A new fusion gene NUP98IQCG identified in an acute T-lymphoid/myeloid leukemia with a t(3;11)(q29q13;p15)del(3)(q29) translocation," Oncogene, vol. 27, no. 24, pp. 3414-3423, 2008.

[269] E. Such, J. Cervera, A. Valencia et al., "A novel NUP98/RARG gene fusion in acute myeloid leukemia resembling acute promyelocytic leukemia," Blood, vol. 117, no. 1, pp. 242-245, 2011.

[270] A. Petit, C. Ragu, G. Soler et al., "Functional analysis of the NUP98-CCDC28A fusion protein," Haematologica, vol. 97, no. 3, pp. 379-387, 2012.

[271] S. Tosi, E. Ballabio, A. Teigler-Schlegel, J. Boultwood, J. Bruch, and J. Harbott, "Characterization of $6 \mathrm{q}$ abnormalities in childhood acute myeloid leukemia and identification of a novel $\mathrm{t}(6 ; 11)(\mathrm{q} 24.1 ; \mathrm{p} 15.5)$ resulting in a NUP98-C6orf80 fusion in a case of acute megakaryoblastic leukemia," Genes Chromosomes and Cancer, vol. 44, no. 3, pp. 225-232, 2005.

[272] P. Gorello, L. Brandimarte, R. La Starza et al., "t(3;11)(q12;p15)/ NUP98-LOC348801 fusion transcript in acute myeloid leukemia," Haematologica, vol. 93, no. 9, pp. 1398-1401, 2008.

[273] S. Saito, K. Nouno, R. Shimizu, M. Yamamoto, and K. Nagata, "Impairment of erythroid and megakaryocytic differentiation by a leukemia-associated and $t(9 ; 9)$-derived fusion gene product, SET/TAF-I $\beta$-CAN/ Nup214," Journal of Cellular Physiology, vol. 214, no. 2, pp. 322-333, 2008.

[274] M. von Lindern, S. van Baal, J. Wiegant, A. Raap, A. Hagemeijer, and G. Grosveld, "can, a putative oncogene associated with myeloid leukemogenesis, may be activated by fusion of its 3' half to different genes: characterization of the set gene," Molecular and Cellular Biology, vol. 12, no. 8, pp. 3346-3355, 1992.

[275] M. von Lindern, M. Fornerod, N. Soekarman et al., "Translocation $\mathrm{t}(6 ; 9)$ in acute non-lymphocytic leukaemia results in the formation of a DEK-CAN fusion gene," Bailliere's Clinical Haematology, vol. 5, no. 4, pp. 857-879, 1992.

[276] W. Deenik, H. B. Beverloo, S. C. P. A. M. van der Poel-van de Luytgaarde et al., "Rapid complete cytogenetic remission after upfront dasatinib monotherapy in a patient with a NUP214ABL1-positive T-cell acute lymphoblastic leukemia," Leukemia, vol. 23, no. 3, pp. 627-629, 2009.

[277] N. Kawamata, L. Zhang, S. Ogawa et al., "Double minute chromosomes containing MYB gene and NUP214-ABL1 fusion gene in T-cell leukemia detected by single nucleotide polymorphism DNA microarray and fluorescence in situ hybridization," Leukemia Research, vol. 33, no. 4, pp. 569-571, 2009.

[278] A. Quintás-Cardama, W. Tong, T. Manshouri et al., "Activity of tyrosine kinase inhibitors against human NUP214-ABL1positive $T$ cell malignancies," Leukemia, vol. 22, no. 6, pp. 1117-1124, 2008. 

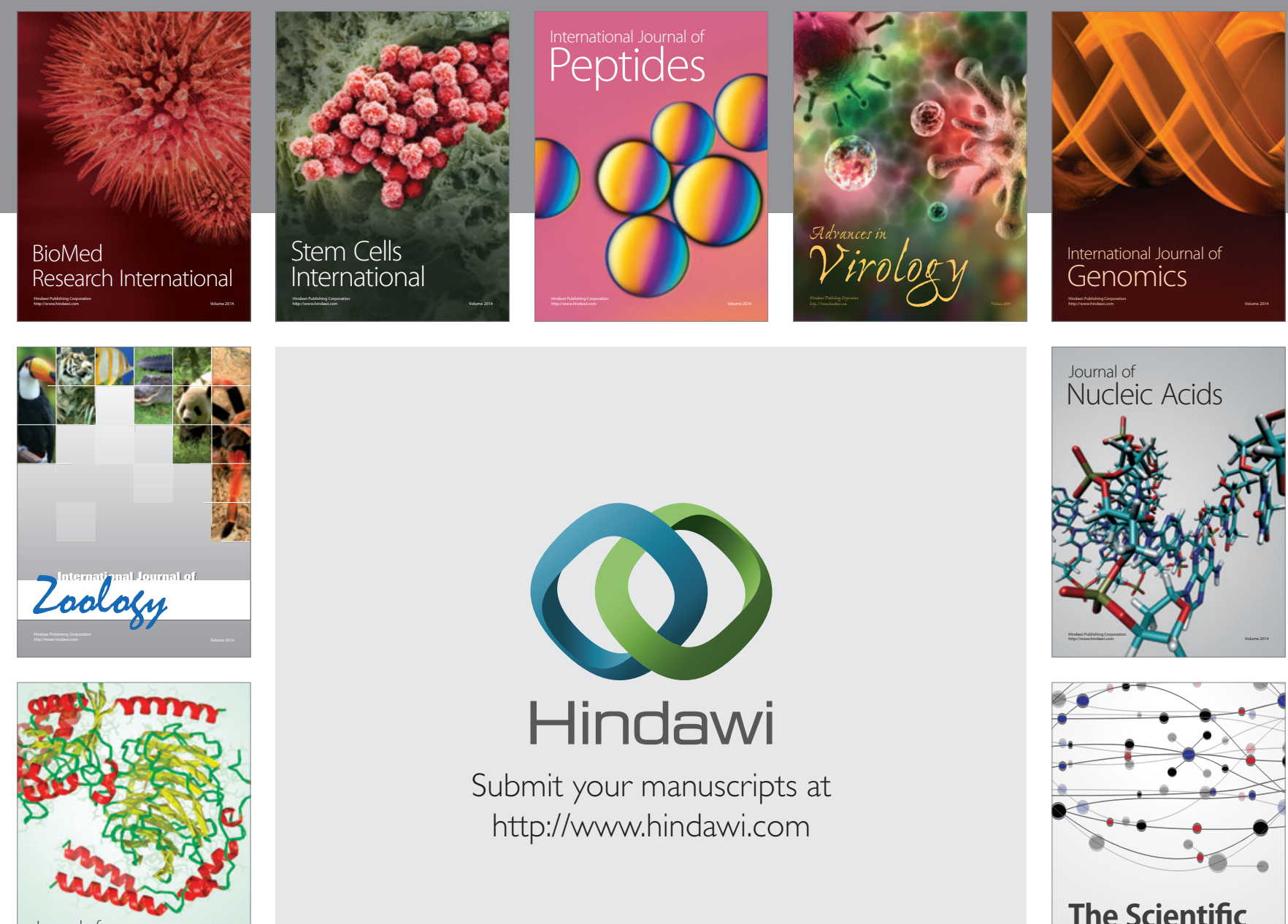

Submit your manuscripts at

http://www.hindawi.com

Journal of
Signal Transduction
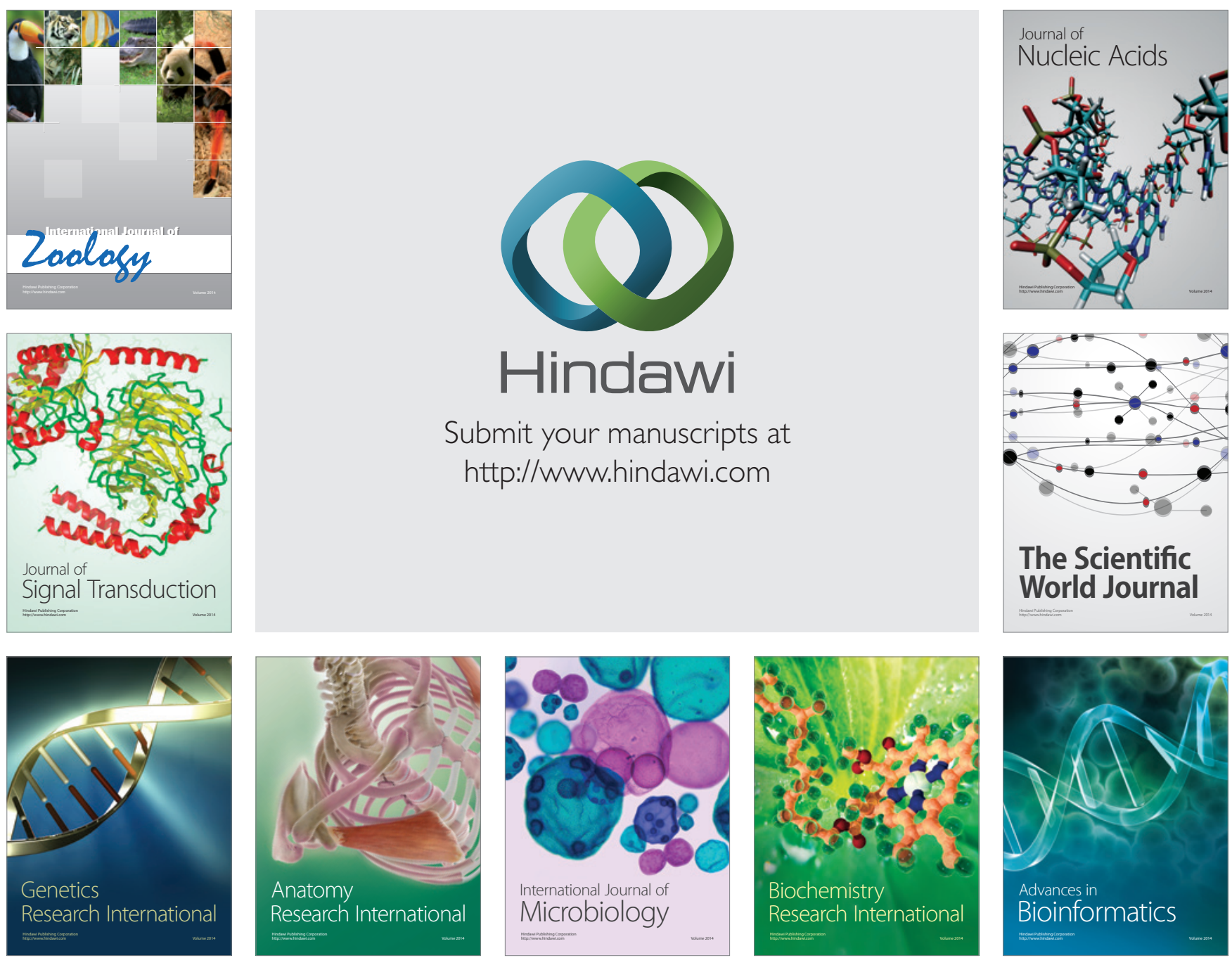

The Scientific World Journal
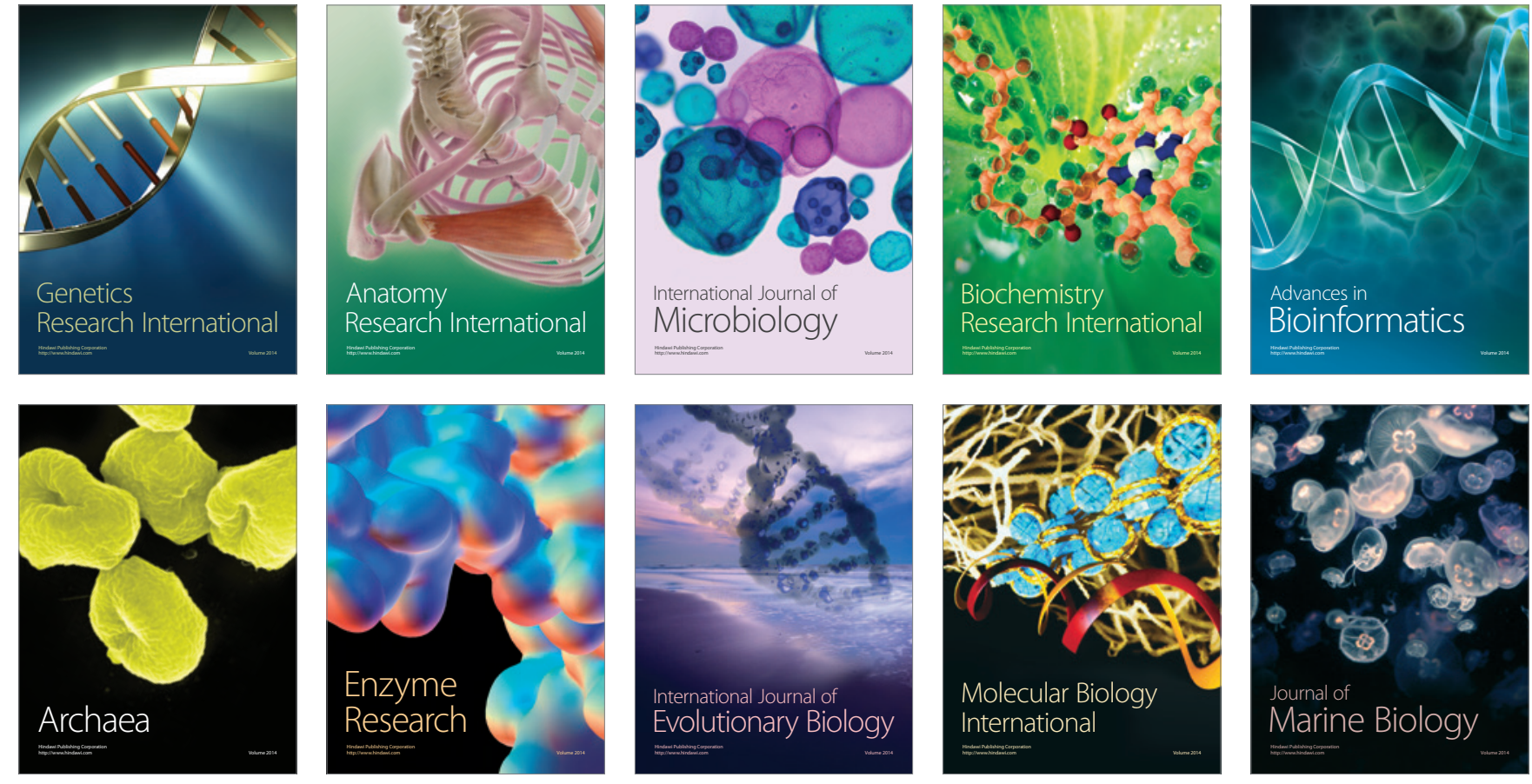